\title{
Improving Feed Slurry \\ Rheology by Colloidal \\ Techniques
}

W. O. Heath

R. L. Ternes

June 1984

Prepared for the U.S. Department of Energy under Contract DE-AC06-76RLO 1830

Pacific Northwest Laboratory Operated for the U.S. Department of Energy by Battelle Memorial Institute 


\title{
DISCLAIMER
}

This report was prepared as an account of work sponsored by an agency of the United States Government. Neither the United States Government nor any agency thereof, nor any of their employees, makes any warranty, express or implied, or assumes any legal liability or responsibility for the accuracy, completeness, or usefulness of any information, apparatus, product, or process disclosed, or represents that its use would not infringe privately owned rights. Reference herein to any specific commercial product, process, or service by trade name, trademark, manufacturer, or otherwise, does not necessarily constitute or imply its endorsement, recommendation, or favoring by the United States Government or any agency thereof. The views and opinions of authors expressed herein do not necessarily state or reflect those of the United States Government or any agency thereof.

\author{
PACIFIC NORTHWEST LABORATORY \\ operated by \\ BATTELLE \\ for the \\ UNITED STATES DEPARTMENT OF ENERGY \\ under Contract DE-AC06-76RLO 1830
}

\begin{tabular}{|c|c|}
\hline \multicolumn{2}{|c|}{$\begin{array}{c}\text { National Technical Information Service } \\
\text { United States Department of Commerce } \\
5285 \text { Port Royal Road } \\
\text { Springfield, Virginia } 22161\end{array}$} \\
\hline \multicolumn{2}{|c|}{$\begin{array}{l}\text { NTIS Price Codes } \\
\text { Microfiche A01 }\end{array}$} \\
\hline \multicolumn{2}{|c|}{ Printed Copy } \\
\hline Pages & $\begin{array}{l}\text { Price } \\
\text { Codes }\end{array}$ \\
\hline $001-025$ & $\mathrm{~A} 02$ \\
\hline $026-050$ & $\mathrm{~A} 03$ \\
\hline $051-075$ & $\mathrm{AOS}$ \\
\hline $076-100$ & A05 \\
\hline $101-125$ & $A 06$ \\
\hline $126-150$ & A07 \\
\hline $151-175$ & $A 08$ \\
\hline $176 \cdot 200$ & $A 09$ \\
\hline $201-225$ & A010 \\
\hline $226-250$ & A011 \\
\hline $251-275$ & $A 012$ \\
\hline $276-300$ & $A 013$ \\
\hline
\end{tabular}


IMPROVING FEED SLURRY RHEOLOGY

BY COLLOIDAL TECHNIQUES

W. 0 . Heath

R. L. Ternes

June 1984

Prepared for

the U.S. Department of Energy

under Contract DE-ACO6-76RLO 1830

Pacific Northwest Laboratory

Richland, Washington 99352 


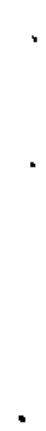

-

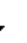




\section{ACKNOWLEDGMENTS}

Considerable effort from other PNL researchers provided a foundation for this research. H. T. Blair (feed transport systems), C. 0. Harvey (feed sample preparation and testing) and G. B. Mellinger (ylass chemistry) are noteworthy in this cateyory. The authors are particularly indebted to the contribution by S. C. Lijkala in conducting laboratory experiments with much creativity and enthusiasm. In preparing this report, comments from R. A. Brouns, M. S. Hanson and $J$. E. Minor were extremely helpful in conjunction with the editing skill and insight provided by J. A. Powell. Finally, the authors wish to thank D. E. Knowiton for his efforts in promoting and maintaining the ideal research environment. 

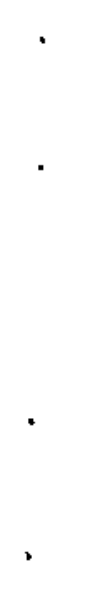
SUMMARY AND CONCLUSIONS

The tendency of simulated melter feed slurries to cloy has imposed unusual constraints on the design of in-cell transport equipment for vitrification of radioactive waste. In a temporary shutdown of the melter feed system, frit or $\mathrm{SiO}_{2}$ particles will begin to settle in process 1 ines and equipment due to loss of turbulence. Within minutes, particles can settle and form a sediment which cannot be resuspended simply by the resumption of fluid motion. Even duriny feed-system operation, such a slurry tends to clog in nonturbulent "dead spots" like T-connections, vaive cavities, vessel bottoms and pump check valves. Thus the primary yoal of rheology alteration is to prevent sedimentation or to make sediments readily resuspendable. An equally important goal of the research is to determine whether feed gellation occurs and, if so, to make the gel restirrable.

Pacific Northwest Laboratory ( $P N L$ ) has investigated three colloidal techniques in the laboratory to improve the sedimentation and flowability of Hanford simulated (nonradioactive) current acid waste (CAW) melter feed slurry:

1. polymer-induced bridging flocculation

2. manipulating glass former (raw $\mathrm{SiO}_{2}$ or frit) particle size

3. alteration of nitric acid content.

All three methods proved successful in improving the rheology of the simulated CAW feed. This initially had exhibited nearly worst-case flow and clogginy properties, but was transformed into a flowable, resuspendable (nonclogying) feed. While each has advantages and disadvantages, the following three specific alternatives proved successful:

1. addition of a polyelectrolyte in 2000 ppm concentration to feed slurry

2. Substitution of a $49 \mathrm{wt} \% \mathrm{SiO}_{2}$ colloidal suspension ( $10-m i c r o n$ particle size) for the -325 mesh ( $\leq 44-$ micron particle size) rawchemical $\mathrm{SiO}_{2}$

3. increase of nitric acid content from the reference $1.06 \mathrm{M}$ to optimum 1.35 M. 
The first method, polymer-induced bridging flocculation, results in a high sediment volume, nonclogging CAW feed. This method is somewhat uncertain since it is not yet known how applicable polymeric materials are in a radioactive stream. However, it is plausible that damaged polymers will still provide stabilization since their most crucial function, adsorption onto glass-former particles, will occur in the nonradioactive gallery mixing vessel. Furthermore, polymeric additives have the decided advantage of being effective over a range of ionic concentration and $\mathrm{pH}$ of the feed. As opposed to colloidal silica, which may be $\mathrm{pH}$ - or ion-sensitive, polymers have the potential of providing a more "universal" applicability.

The second method, involving the use of colloidal silica particles results in a nonsedimenting feed that when left unagitated forms a gel. The gel formed is normally loose and easily refluidized using air sparging or normal pumping action. The colloidal silica suspension consists of $51 \%$ water and may therefore cause excessive feed dilution, although in at least two conceptual vitrification processes (HWVP and DWPF), this dilution is not considered a problem. In addition, the possibility of forming a stiffer, less resuspendable gel has been demonstrated, although never under normal processing conditions. Finally, the use of colloidal silica may cause an overall reduction in melting (processing) rates, although this has yet to be established conclusively.

The third method, increase in feed acidity, results in a highly resuspendable (nonclogging) melter feed. Although this method may be undesirable due to increased corrosion in feed-transport equipment and increased nitrate recovery load in melter off-gas equipment, it must be determined to what extent corrosion and off-gas loading will be increased since an increase from $1.06 \mathrm{M}$ to $1.35 \mathrm{M}$ nitric acid content may not be significant.

Further research is therefore required to determine which of the three alternatives is the preferred method of achieving rheological control of CAW melter feeds.

In addition to CAW feed, research was also carried out on West valley acid waste (WVAW). A resuspendable WVAW melter feed was achieved by using raw $\mathrm{SiO}_{2}$ particles ( -325 mesh) rather than muticomponent frit particles ( -325 mesh) as 
the glass formers. It is probable that the high-viscosity range of WVAW (10 to $10^{3}$ (centipoise) imposes sufficient viscous drag to maintain the $\leq 44-m i c r o n$ $\mathrm{SiO}_{2}$ particles in suspension for a relatively long time. Even after several days left unagitated, the WVW melter feed can be easily resuspended, and is thus a nonclogging feed.

A brief study on adverse feed gellation indicated that stiff, nonflowable gels were not formed by either CAW or WVAW when their reference glass formers were used. However, when a nonreference glass former (SRL Frit-131) was used with WVAW, a thick, solid-like, gelled sediment was formed that would almost certainly lead to clogging. Although that combination of simulated waste and glass former will never be used, it was felt that the potential for such difficulty exists and should be dealt with. An innovative method was developed to prevent gellation in this nonreference feed.

The achievement of improved rheology was demonstrated in the August and September 1983 nonradioactive pilot-scale melter runs for the West valley Support and Hanford Waste Vitrification Proyrams, respectively, where an unprecedented lack of feed-related problems was experienced. This initial use of colloidal techniques to improve the flow properties of acidic melter feed should be followed with additional studies of simulated neutrailized feed and finally of radioactive feed. Within polymers, and colloidal techniques in general, lies the potential long-term solution to melter feeding problems. 

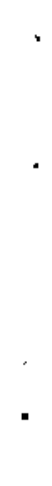

. 


\section{CONTENTS}

ACKNOWLEDGMENTS......................................

SUMMARY AND CONCLUSIONS..............................

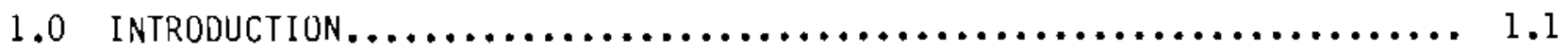

1.1 HIGH-LEVEL WASTE IMMOBILIZATION ................... 1.1

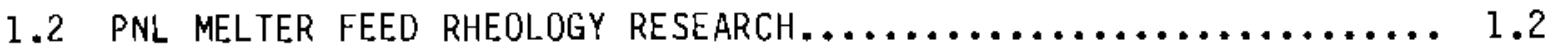

2.0 DISPERSIDN STABILITY: RELEVANT COLLOIDAL THEORY.............. 2.1

2.1 CLASSIFICATION OF MELTER FEEDS $\ldots \ldots \ldots \ldots \ldots \ldots \ldots \ldots \ldots \ldots \ldots \ldots \ldots \ldots$

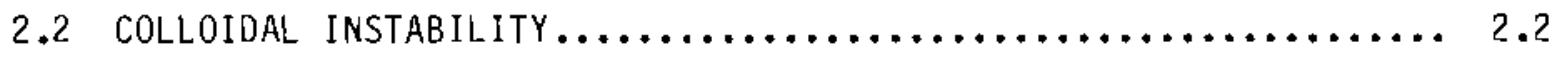

2.2 .1 Flocculation............................. 2.3

2.2.2 Particle Size Disproportionation................ 2.4

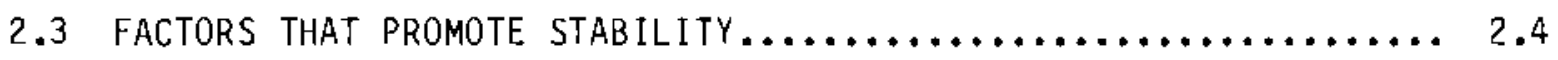

2.3 .1 Thermal Agitation......................... 2.4

2.3.2 Reverse Particle Diffusion........................ 2.5

2.3.3 Electrical Double-Layer Overlap................. 2.5

2.3.4 Electroviscous Effects..................... 2.6

2.3.5 Steric Stabilization........................ 2.7

2.3 .6 Bridging Flocculation...................... 2.7

3.0 SEDIMENT FORMATION: RELEVANT COLLOIDAL THEORY............... 3.1

3.1 NONFLOCCULATED SEDIMENTATION...................... 3.1

3.1.1 Capillary Resistance........................ 3.1

3.1.2 Morphological Effects....................... 3.2

3.1.3 Solids Bridging........................... 3.2

3.2 Flocculated Sedimentation........................ 3.3

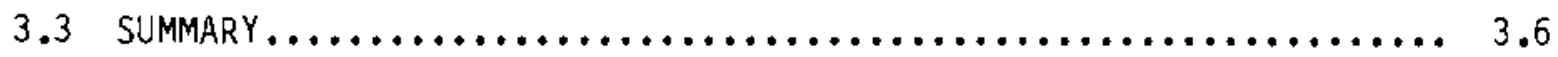


4.0 GENERAL RESULTS: COLLOIDAL TECHNIQUES APPLIED TO SLURRY RHEOLOGY.... 4.1

4.1 HANFORD CURRENT ACIO WASTE (CAW) RESEARCH............... 4.1

4.1 .1 Manipulation of Particle Size................... 4.2

4.1 .2 Manipulation of Nitric Acid Concentration........... 4.4

4.1 .3 Polymer-Induced Flocculation................... 4.5

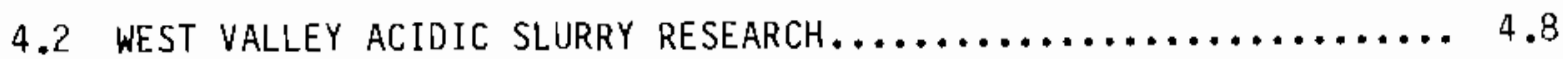

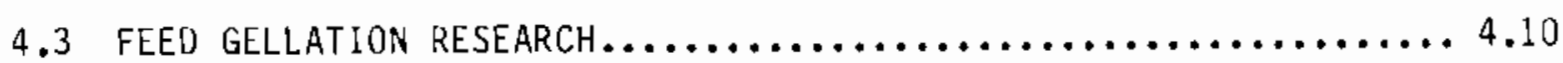

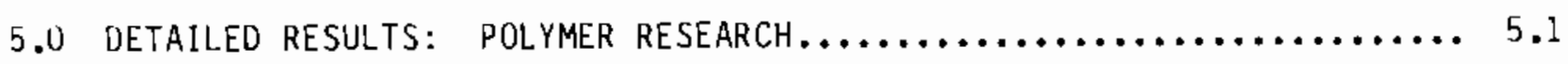

5.1 SUMMARY.................................... 5.1

5.2 Description OF POLYMERS InVESTIGATED $\ldots \ldots \ldots \ldots \ldots \ldots \ldots \ldots \ldots \ldots \ldots$

5.3 METhOD AND RESULTS............................. 5.3

5.3 .1 Polyethylene $0 x i d e s \ldots \ldots \ldots \ldots \ldots \ldots \ldots \ldots \ldots \ldots \ldots \ldots .4$

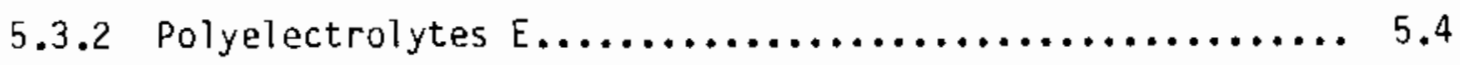

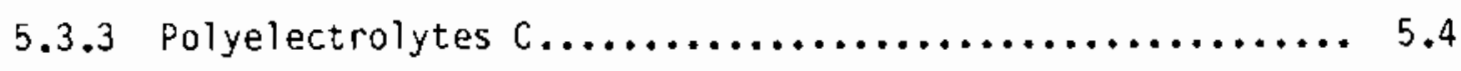

5.3 .4 Polyelectrolytes B......................... 5.5

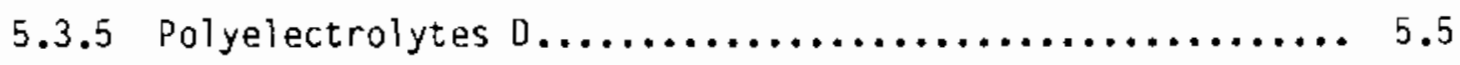

5.4 EFFECT OF NITRIC ACIO CONCENTRATION ON POLYMER STABILIZATION... 5.5

5.5 EFFECT OF METHOD OF POLYMER ADDITION ON STABILIZATION ........ 5.6

6.0 IMPACT OF COLLOIDAL TECHNIQUES ON RADIOACTIVE WASTE GLASS-MAKING..... 6.1

6.1 COLD-CAP PRDPERTIES ........................... 6.1

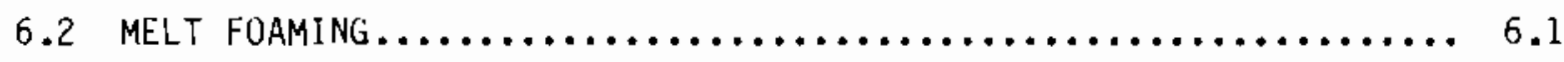

6.3 GLASS-REDUCING EFFECTS $\ldots \ldots \ldots \ldots \ldots \ldots \ldots \ldots \ldots \ldots \ldots \ldots \ldots \ldots \ldots \ldots$

6.4 BORON VOLATILITY............................. 6.3

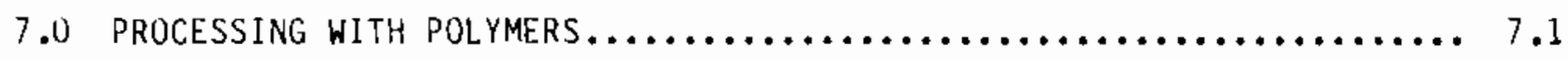

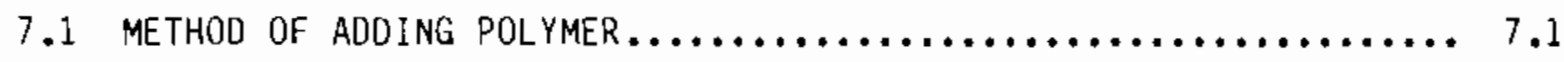

7.2 SOLIDS LOADING IN GLASS-FORMER STREAM $\ldots \ldots \ldots \ldots \ldots \ldots \ldots \ldots \ldots \ldots . \ldots \ldots$ 
7.3 IMPACT ON CONSTRAINTS IN EQUIPMENT DESIGN.............. 7.2

7.4 IMPACT ON PROCESS QUALITY CONTROL $\ldots \ldots \ldots \ldots \ldots \ldots \ldots \ldots \ldots \ldots \ldots . . . \ldots \ldots$

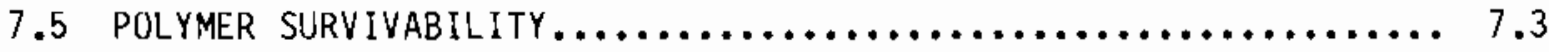

7.6 UNIVERSAL APPLICABILITY OF POLYMERS $\ldots \ldots \ldots \ldots \ldots \ldots \ldots \ldots \ldots \ldots \ldots$

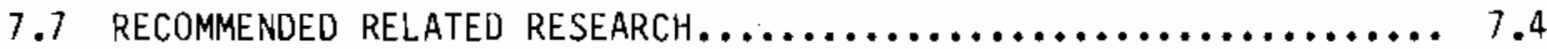

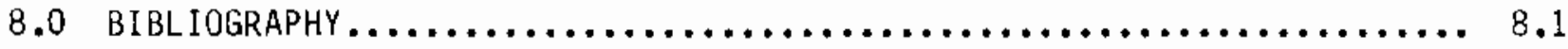
APPENDIX A: COMPOSITION OF CAW AND WEST VALLEY ACID FEEOS ............ A.I APPENDIX B: SIMULATED FEED PHYSICAL PROPERTY DATA $\ldots \ldots \ldots \ldots \ldots \ldots \ldots \ldots \ldots \ldots . \ldots$ 


\section{FIGURES}

1. Close Approach of Sterically Stabilized Colloid Particles.......... 2.8

2. Sedimentation in Flocculating and Nonflocculating Systems......... 3.4

3. Sediment Volume Increase due to Addition of Polymer.............. 3.5

4. Effect of Nitric Acid Content on CAW Feed................... 4.6

5. Polymer Effects on CAW Slurry Volume...................... 4.7

6. Polymer-Induced Resuspendability........................ 4.8

7. Comparison of Sedimentation Processes: Nonflocculating, Spontaneous Flocculation, Polymer-Induced Bridging Flocculation....................................... 5.2

8. Polymer Structure.................................. 5.3

\section{TABLES}

1. Frit $82-10$ 0xide Composition.......................... 2.2

2. CAW Raw-Chemical Glass Formers......................... 2.2

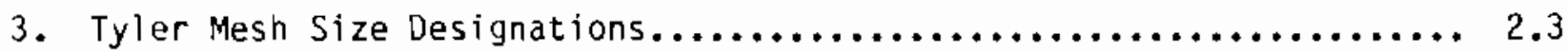

4. Effect of Nitric Acid Addition on CAW Slurry Sediment Volume........ 4.5

5. Slurry Gelling Behavior.............................. 4.10

6. Comparison of Glass-Former Oxide Compositions, wt.............4.10

7. Acid Concentration Dependence of $01 \ldots \ldots \ldots \ldots \ldots \ldots \ldots \ldots \ldots \ldots \ldots \ldots . \ldots \ldots$ 


\subsection{INTROOUCTION}

The goal of the work described here is to develop the understanding and techniques required to produce slurries consisting of simulated radioactive waste and glass former particles that are transportable in remote-cell slurry feed systems. This report summarizes and documents the developinent, at the Pacific Northwest Laboratory (PNL), of melter feed slurry rheology modification techniques to a current level of applicability. The relevant theories of colloidal science, used to successfully modify the rheology of melter feeds, are presented only in sufficient detail to allow an understanding of why the currently employed techniques work, what their limitations are, and which techniques have the greatest potential for favorably and adequately modifying radioactive melter feeds.

The work was done in support of the Department of Energy's (DOE) Hanford Waste Vitrification Program (HWVP) and Civilian Nuclear Waste Treatment Program (CNWTP $^{(a)}$ at the Pacific Northwest Laboratory operated by Battelle Memorial Institute for DOE. Both programs have the task of documenting and demonstrating the technology of high-level radioactive waste (HLW) vitrification.

\subsection{HIGH-LEVEL WASTE IMMOB ILIZATION}

Military and civilian applications of nuclear technology in the U.S. and throughout the world have generated an inventory of high-level radioactive wastes. This material is accumulated in temporary storage facilities as solutions and sludges where it is isolated from the environment. Since the liquids are not an acceptable form for permanent storage of high level wastes, environmentally acceptabie methods of reducing the volume of, immobilizing, and permanently storing high-level waste have received the support of the Departinent of Energy.

(a) Until January 1984 the CNWTP was the Commercial Waste Treatment Program (CWTP). 
Vitrification, the process of containing radioactive particles in a stable glass product, has been developed into a technically feasible and environmentally acceptable method of immobilizing high-level wastes. The glass product is relatively insoluble, resistant to chemical attack, physically durable and well suited for dissipating decay heat and resisting radiation damage.

PNL has demonstrated the vitrification technology using non-radioactive simulated waste, and has conducted limited demonstrations of the vitrification of liquid high level radioactive wastes by the in-can melting process. A current task of PNL is to demonstrate the vitrification of high-level radioactive waste using the Liquid Fed Ceramic Melter Technology. The first stage, adaptation of process equipment designs to remote service operation, is nearing completion, and the construction of a pilot-scale remote facility is under way. In this manner, the commercial feasibility of vitrification is being demonstrated. In addition, a recent study (Larson et al. 1983) indicates that beyond its potential to provide excellent waste-volume reduction and safe immobilization, vitrification will be economically competitive with current, less desirable forms of radioactive waste-volume reduction and immobilization.

\subsection{PNL MELTER FEED RHEOLOGY RESEARCH}

In the vitrification of HLW the waste stream is mixed with glass-forming particles and melted into a stable glass product.

At PNL the vitrification process is operated semi-continuously and consists of the following basic processing steps:

1. concentration of $\mathrm{HLW}$

2. mixing of concentrated HLW with glass formers to make up the process feed

3. transport of the feed from the make-up vessel to the melter

4. drying and melting of the process feed in the melter

5. collection and decontamination of the volatiles in an off-gas system

6. encapsulation and cooling of the molten glass product in canisters. 
This report is concerned mainly with the transportability of the process feed stream, and thus focuses on the rheology of process feed streams. Briefly, rheology is a collective property that encompasses both the flow and sedimentation properties of a slurry. Properties that affect the flow, such as viscosity, are rheological variables, as are factors that affect sedimentation, such as particle size. Most rheological variables influence both the flow and sedimentation characteristics of a slurry, as do viscosity and particle size. "Rheology" should therefore be understood as a set of properties and is thus complex by nature.

As a rule, the transport of melter feed slurries has been problematic. All melter feeds contain solids, mainly crushed glass-formers, that are large enough and of sufficient density to settle unless maintained in suspension by external agitation or turbulence. Unfortunately, providing sufficient agitation or turbulent flow at all points from the feed make-up vessel to the melter feed nozzle is extremely difficult as illustrated next.

Consider a horizontal feed line extending from the feed make-up vessel to the melter, and for simplicity assume the pipe is featureless (no valves, fittings, bends, etc.). The criterion for turbulence will be that the dimensionless Reynolds number $\left(N_{R E}=\frac{\rho D \vec{v}}{\mu}\right)$, which is the ratio of inertial forces to viscous forces, is greater than 2100.(a) A simple calculation can be performed to determine whether flow in the feed line is turbulent, but to do this, the pipe diameter, volumetric flow rate and fiuid properties of the feed must be known.

The inner diameter (D) of the pipe must be at least as large as the Targest particles to be transported. A minimum diameter of $1 / 4 \mathrm{in}$. is reasonable since particles approaching that diameter may be encountered.

(a) This criterion is actually for transition flow, or the onset of turbulence. Fully turbulent flow is most often considered as occurring at $\mathrm{N}_{R E} \geq 4000$ (Denn 1980). In addition, this assumes that the Reynolds turbulence criterja is the same for a nonnewtonian colloidal suspension as it is for newtonian fluids. 
A typical melter feed system flow rate, $\dot{v}$, ranges between 60 and 120 liters per hour. Specific gravity of most melter feeds is around 1.40 , while viscosity ranges from 10 to $10^{3}$ centipoise and higher.

The highest possible $N_{R E}$ will occur assuming a high feed rate of 120 liters per hour and a low viscosity of $10 \mathrm{cp}$ :

$$
\mathrm{N}_{\mathrm{RE}}=\frac{\rho \mathrm{D} \vec{v}}{\mu}=\frac{(1.40)(0.635)(105.25)}{(0.10)}=935.7
$$

where: $\rho=1.40 \mathrm{~g} / \mathrm{cm}^{3}$

$$
\begin{aligned}
& 0=(0.25)(2.54)=0.635 \mathrm{~cm} \\
& \vec{v}=\frac{\dot{v}}{\frac{\pi D^{2}}{4}}=\frac{(120)(4)}{\pi(0.635)^{2}} \cdot \frac{1000}{3600}=105.25 \frac{\mathrm{cm}}{\mathrm{s}} \\
& \mu=\frac{10}{100}=0.10 \text { poise }=0.10 \frac{\mathrm{g}}{\mathrm{cm}} \cdot \overline{\mathrm{s}}
\end{aligned}
$$

Therefore, assuming a minimum feed line diameter of $1 / 4 \mathrm{in.}$, a maximum feed flow of 120 liters per hour, and that some horizontal distance must be traversed between the feed make-up tank and the melter, flow within the feed line will be laminar rather than turbulent. Thus sedimentation is predicted(a)

Since, as detailed in this report, most feed sediments exhibit a shear resistance, or dilatancy, and are thus nonresuspendable, complete line-clogging can occur. When fittings and T-connections (as for flush lines) are introduced, stagnant flow areas are created that even worsen the problem. Further, since the dilatant sediments are nonresuspendable, permanent clogs can form that cannot be easily flushed out. Because of the radioactivity of the feed, vitrification is performed in a remote access cell, thus complicating or even precluding otherwise simple maintenance procedures. The entire vitrification process will be performed remotely, using cranes and manipulators with television monitor viewing. A crane provides the capability to raise and lower objects, while a manipulator can grasp objects and perform simple

(a) Similar calculations predict that for $\mathrm{N}_{R E}=2100$, a feed line diameter of $\sim 1 / 10 \mathrm{in}$. is required, and for $\mathrm{N}_{\mathrm{RE}}=4000$, a diameter of $\sim 1 / 16 \mathrm{in}$. 
tasks. It is the inhomogeneity of melter feeds, coupled with low flow rate and remote operation, that causes feed transport to be problematic by nature.

It has been shown, based on research with nonradioactive (simulated) melter feeds that the rheology of melter feeds in general can be modified to produce easily transportable feeds. The modified feeds have exhibited, in all cases, no clog-forming tendencies.

During the August and September 1983 HWV (defense waste) and West Valley (civilian waste) nonradioactive pilot-scale runs, an unprecedented lack of feed transport problems was experienced, due mainly to the successful rheological improvement of the Hanford CAW and West Valley acid waste feed slurries. In addition to developmental work in support of the Hanford and west valley melter runs, the capability to alter actual high-level waste feeds is in the conceptual stage and appears very promising. The most positive and universally applicable method of producing an easily transportable feed appears to be via the addition of polymers. 
,

.

.

. 


\subsection{DISPERSION STABILITY: RELEVANT COLLOIDAL THEORY}

Colloidal systems consist of a dispersed phase and a continuous phase. In the classic colloidal system, the dispersed phase consists of particles or aroplets in the 0.001 to 10 -micron range, although particles up to 100 microns in size may behave like colloids and thus fall within the scope of understanding of colloids.

\subsection{CLASSIFICATION OF MELTER FEEDS}

The colloidal systens of current interest are dispersions composed of simulated (nonradioactive) high-level nuclear waste $(a, b)$ as the continuous phase and of glass-former particles as the dispersed phase. (c) The insoluble glass formers are generally either frits (multicomponent ground glass powder) or separate, single-component glass formers (oxides, nitrates, etc.).

Table 1 lists the composition of a multicomponent frit (Frit 82-10) specified for the Hanford current acid waste (CAW). Table 2 lists the colnbination of single components required to replace Frit 82-10 as substitute (raw chemical) glass formers.

As the dispersed phase, all the frits studied (including Frit 82-10) are relatively insoluble in the waste streams, while of the glass formers only $\mathrm{SiO}_{2}$ is insoluble.(d) The insoluble $\mathrm{SiO}_{2}$ and frit particles are classified as lyophobic, or "solvent-hating," particles since a true particle/waste interface

(a) Simulated waste compositions are shown in Appendix A of the report.

(b) In this study, all waste streams contained only soluble species. However, many wastes (e.g., neutralized waste) contain insoluble solids and are thenselves slurries and possibly colloidal suspensions (depending on the particle size range).

(c) A dispersion, or suspension, in general contains only particles within the classic colloidal size ranye (1-10 microns) whereas a slurry may contain particles or aggregates having larger than colloidal dimensions. The terms "dispersion" and "slurry" are not completely interchangeable.

(d) Anhydrous sodium borate $\left(\mathrm{Na}_{2} \mathrm{~B}_{4} \mathrm{O}_{7}\right)$ is a virtually insoluble boron source that can always be substituted with hydrated sodium borate. It is assumed here that the soluble species is used. The effect of insoluble sodium borate on feed rheology is described in Sections 6.2 and 6.4 . 
TABLE 1. Frit 82-10 0xide Composition

$\begin{array}{lr}\mathrm{SiO}_{2} & \frac{w t \%}{61.7} \\ \mathrm{~B}_{2} \mathrm{O}_{3} & 15.1 \\ \mathrm{Na}_{2} \mathrm{O} & 14.7 \\ \mathrm{Li}_{2} \mathrm{O} & 7.4 \\ \mathrm{MgO} & \underline{1.1} \\ & 100 \%\end{array}$

TABLE 2. CAW Raw-Chemical Giass Formers

exists. (Lyophilic, or "solvent-loving," particles are not really particles, but dissolved macromolecules (e.g., polymers) or aggregates of smaller molecules that form true thermodynamic solutions rather than dispersions.)

The two most commonly specified frit and $\mathrm{SiO}_{2}$ particle sizes at PNL are -325 mesh and -200 mesh; the number indicates the Tyler mesh size and the minus sign indicates that the particles all pass through the mesh and are thus the same size as or smaller than the mesh openings. Table 3 shows the relationships between Tyler mesh size and the corresponding upper particle size cutoff in microns. In this study, all $\mathrm{SiO}_{2}$ and frit particles are -325 mesh, or up to 44 microns in size and are thus within the upper range of colloidal dimensions (less than 100 microns).

\subsection{COLLOIDAL INSTABILITY}

All lyophobic colloidal dispersions are thermodynamically unstable with respect to sedimentation when the dispersed phase is more dense than the continuous phase (as with waste/glass-former dispersions). (a) As discussed next, both flocculation and particle size disproportionation can increase the instability of sedimentation.

(a) Sedimentation is the spatial variation of the particle concentration where the higher concentration is in the lower portion of the dispersion. It occurs by virtue of a gravitational field although it can be enhanced by centrifugation and by an applied electric (DC) field (Dorn effect). 
TABLE 3. Tyler Mesh Size Designations (a)

\begin{tabular}{|c|c|}
\hline $\begin{array}{l}\text { Particle } \\
\text { Size, } 1 \mathrm{~m}\end{array}$ & $\begin{array}{c}\text { Tyler } \\
\text { Mesh No. }\end{array}$ \\
\hline 125 & 120 \\
\hline 105 & 140 \\
\hline 88 & 170 \\
\hline 74 & 200 \\
\hline 63 & 230 \\
\hline 53 & 270 \\
\hline 44 & 325 \\
\hline 37 & 400 \\
\hline
\end{tabular}
(a) From Perry and Chilton et al., pp. 21-41.

\subsubsection{Flocculation}

Flocculation is the sticking together of particles to form flocs. The sedimentation rate can be increased by flocculation since flocs of particles may have higher terminal velocities than do individual particles (due to a decrease in the area/volume ratio). (a) This is often the case when spherical flocs are formed. In other cases, flocculation can prevent sedimentation when the flocs consist of several particles in a chain. These chains can become sufficiently cross-linked that the flocculated system consists more of a single, cross-linked floc extending throughout the continuous phase. A gel is an example of an extensive, single-floc system. Flocculation can therefore result in systems varying in heterogeneity from rigid sediments to loosely structured gels.

\footnotetext{
(a) Flocculation occurs by virtue of the so-called "long-range" van de Waals forces of interparticle attraction and is usually spontaneous, if it occurs at all.
} 


\subsubsection{Particle Size Disproportionation}

Another factor that assists sedimentation is particle size disproportionation, where the large particles grow larger at the expense of the smaller ones. (a) This process occurs most rapidly when the particles are sijightly soluble in the solvent, as are frits and $\mathrm{SiO}_{2}$ in acid waste. (b) In our case, however, it is unlikely that size disproportionation is important since the time during which glass-former/waste suspensions will be maintained in-cell is relatively short (less than 1 week). Still, waste slurry samples allowed to sit for months between experiments may exhibit a greater tendency towards sedimentation and should thus be prepared "freshly" for at least this reason. (A more important reason is that the soluble species combined in a frit, such as $\mathrm{B}_{2} \mathrm{O}_{3}$ and $\mathrm{Na}_{2} \mathrm{O}$, will tend to leach out and leave behind an $\mathrm{SiO}_{2}$ "shell," thus causing the aged sample to be further nonrepresentative.)

\subsection{FACTORS THAT PROMOTE STABILITY}

Factors that oppose either flocculation or sedimentation (or both) include: thermal agitation; reverse particle diffusion; electrical doublelayer repulsion; electroviscous effects; and steric stabilization due to the presence of an adsorbed layer of polymeric material. These factors, discussed next, complete the yeneral treatment of colloidal theory.

\subsubsection{Thermal Ayitation}

Thermal ayitation is of primary importance when particles are in the classic colloidal range of 1 to 10 microns; therefore it affects only a portion of the -325 mesh particle distribution. Thermal agitation is the manifestation of the kinetic energy of each particle that derives from its absolute temperature. The higher the absolute temperature of the colloidal system, the more intrinsic

(a) The driving force for size disproportionation is the reduction of particle surface free energy (analogous to the surface tension of liquids). The lower the overall surface free energy the more stable the system with respect to change.

(b) The solubility of $\mathrm{SiO}_{2}$ is strongly dependent upon temperature, $\mathrm{pH}$, particle size, particle asperity (surface roughness) and the presence of impurities, most notably $\mathrm{Al}_{2} \mathrm{O}_{3}$, which has been found to reduce $\mathrm{SiO}_{2}$ solubility by an order of magnitude (Iler 1979). 
energy is carried by the particles and the less likely they are to stay confined to a floc. Thermal agitation is also largely responsible for maintaining particles in suspension since thermal energy is transmitted from the constantly moving microscopic solvent molecules to the colloidal glass former particles. This scenario has been described as "a Goodyear blimp being bombarded by mi1lions of basketballs" (Berg 1981). The smaller individual particles are held in suspension by the bombardment of solvent molecules.

\subsubsection{Reverse Particle Diffusion}

Reverse particle diffusion is of the most importance in the subricron range. It is a process of mass transfer that is by the concentration gradient formed by sedimenting solids. In our case, reverse particle diffusion would merely slow the already sluggish sedimentation velocity of the smallest solids within a nonflocculating waste/glass former slurry, thus helping to maintain the "smeared out" interface in a sedimented system. (In general, if flocculation is complete, even the smallest particles will have aggregated and sedimented, leaving a sharp sediment/solvent interface.)

\subsubsection{Electrical Double-Layer Overlap}

Electrical double-layer overlap opposes flocculation when colloid particles carry similar charges in a low-ion-concentration solution $\left(10^{-8}\right.$ to $\left.10^{-4} \mathrm{M}\right)$. In aqueous solution, most colloidal particles carry a negative charge due to the preferential adsorption of anions. (a) positively charged counter ions, or gegen ions, are attracted to the colloidal particles and distribute themselves in the solution surrounding them; the cations required to neutralize the charge of the particle do not actually adsorb onto the anionic surface. The cations concentrate near the particle surface; thermal agitation decreases this concentration with distance from the anionic particle. This distribution of separated positive and negative charges sets up an electric field which, in colloidal science, is known as the electrical double layer. The particles will

(a) However, many oxygen-containing minerals, such as $\mathrm{SiO}_{2}$, carry either a positive or negative charge, depending on $\mathrm{pH}$. In this instance, $\mathrm{H}^{+}$and $\mathrm{OH}^{-}$are the so-called potential determining ions. We will assume, for the discussion, that the $\mathrm{SiO}_{2}$ particle surface in acidic waste is negatively charged. 
be inhibited from flocculating if these electrical double layers extend so far from the particle that the "long-range" van der wals attractive forces are exceeded by the electrostatic repulsion, which is generated by the impinging, similarly-charged double layers of two approaching colloids.

The size of these double layers depends strongly on the valency of the cations comprising the diffuse double layer. If high-valency $(+3)$ cations are present $\left(\right.$ e.g., $\left.A 1^{+3}\right)$, the double layer will be much thinner than when only $(+1)$ cations are present. This means that if high-valency gegen ions (in this case, cations) are in solution, the double layers will be quite small and van der wals attractive forces can overcome electrostatic repulsion so that flocculation occurs. (a)

In all waste/glass-former dispersions the electrical double layer is expected to be of negligible thickness due to the strong overall ionic concentration of the waste stream amplified by the presence of polyvalent ions. Therefore, flocculation is to be expected in the absence of other considerations.

\subsubsection{Electroviscous Effects}

Electroviscosity is an electrostatically generated resistance to particle flow. Electroviscous effects are not important when particle size exceeds 20 microns and electrical double layer thickness is negligible. With one glass former studied (10-micron $\mathrm{SiO}_{2}$ in water), electroviscosity increased viscosity by an order of magnitude, with viscosity increasing with shear rate. This phenomenon could substantially affect pump sizing criteria over what would be suggested using the usual viscosity correlations(b) and may limit the flow velocity through the cell wall to the feed make-up tank if a 10 -micron $\mathrm{SiO}_{2}$ dispersion is used. Also, a DC electric field will be created and potential drops in the hundreds of volts may be achieved. For this reason, it may be necessary to electrically ground the glass-former add line and pump.

(a) For a useful discussion and graphic representation of the electrical double layer, see Chapter 3 of Van 01 phen (1977).

(b) The Einstein equation and related empirical equations are common viscosity versus volume percent solids correlations that do not account for important electroviscous effects. 


\subsubsection{Steric Stabilization}

Surface-active polymeric materials adsorbed at a particle surface can inhibit flocculation. This is known as steric stabilization. This terminology is misleading in implying that particles are stabilized through geometric factors; in truth, stabilization is achieved through thermodynamic factors. In Figure 1 (adapted from Berg), we see two approaching particles that have adsorbed polymer covering their surface. As the particles approach so closely that the polymer chains interpenetrate, the two free-energy contributions, enthalpy and entropy, must be considered. The combination of signs (+ or -) and their magnitudes governs the sign of the free-energy change of close approach. The latter governs whether or not close approach can occur, as described by the Gibbs free-energy equation $\Delta G=\Delta H-T \Delta S$. The physical interpretation of the behavior is somewhat involved. Suffice it to say that stabilization can be achieved by polymer adsorption under the proper conditions of
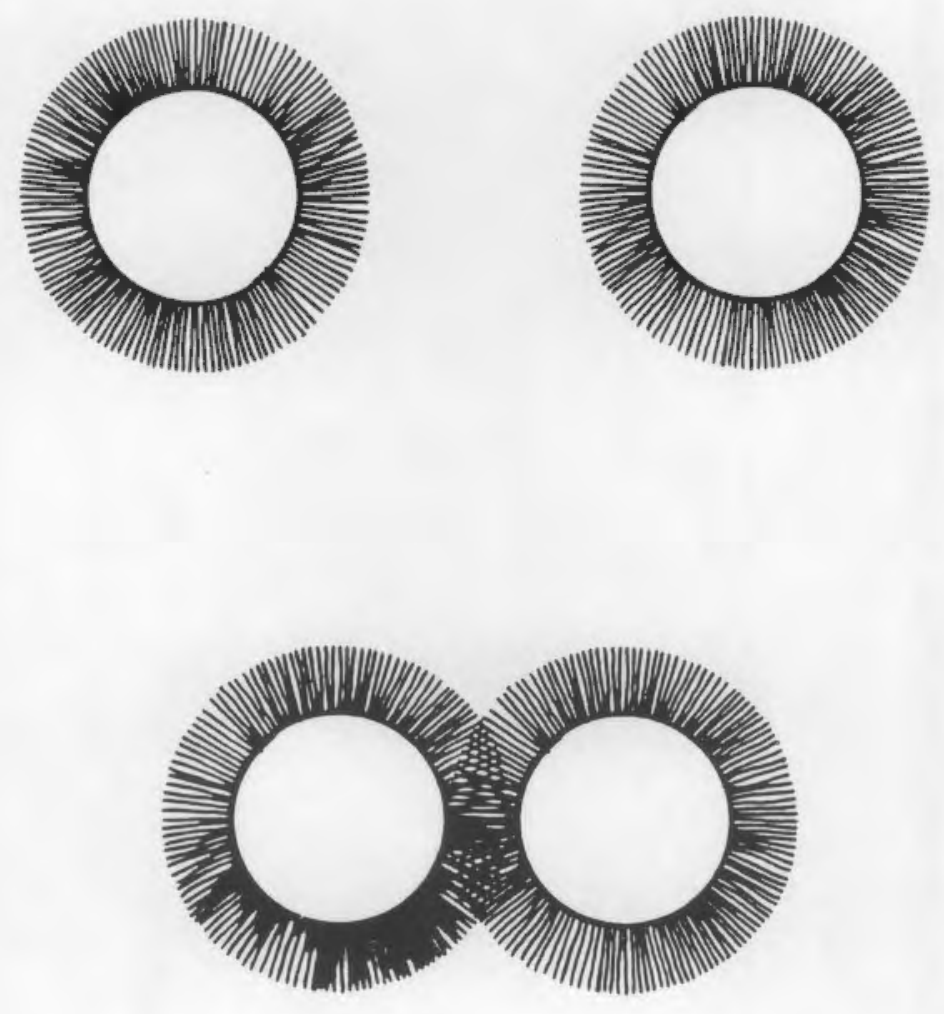

FIGURE 1. Close Approach of Sterically Stabilized Colloid Particles 
polymer concentration and molecular weight. Polymers of molecular weight as low as 500, but usually 10,000 or higher, are used to achieve steric stabilization (Berg 1981).

\subsubsection{Bridging Flocculation}

An interesting, and in this study, crucial, sidelight on steric stabilization is that adsorbed polymers can, under the proper conditions, also induce flocculation rather than inhibit it. This phenomenon, known as "bridgingflocculation," occurs when the adsorbed polymer covers less than half of the surface of the colloid and the polymer itself has a very high molecular weight (in the millions). The operational principle is that the long polymer molecule can adsorb onto two or more particles simultaneously and thus tie them into loose flocs. 


\subsection{SEDIMENT FORMATION: RELEVANT COLLOIDAL THEORY}

The sediments formed when frit or $\mathrm{SiD}_{2}$ particles are allowed to "settle out" have been found to be of two general types: resuspendable (reversible) and nonresuspendable (irreversible). In particular, when Hanford Frit 82-10 is mixed with simulated CAW to form Hanford CAW melter feed, the sediment formed is irreversible. However, when a flocculating agent is mixed in small amounts into the CAW feed, the sediment formed is completely reversible (easily resuspended). Since sedimentation can occur within minutes in process lines and equipment when pipe flow or agitation is reduced and since a certain degree of sedimentation will always occur in dead spots (areas of nonturbulence), the implication of a melter feed that forms a nonresuspendable sediment or irreversible cloy is clear. There would be no assurance that line flushing could remove the line clogs or that resumption of agitation in the feed make-up vessel would be possible. In the event of pump failure, the feed line would need to be removed if flushing is not immediately used to prevent complete in-line settling. Even in pilot-scale nonremote testing, line clogging often occurred. General methods for producing a resuspendable sediment are discussed below, and methods employed successfully with the CAW melter feed are discussed in Section 4.1 .

\subsection{NONFLOCCULATED SEDIMENTATION}

The rheological properties of a densely packed, nonflocculated sediment are much different from those of a relatively voluminous, loosely packed flocculated sediment.

\subsubsection{Capillary Resistance}

In a nonflocculating system (e.g., CAW/Frit 82-10), the single particles settle and form a dense sediment with a low pore volume and thus with only small interstitial spaces between particles. Because of the natural tightness of the packing, the interstices behave like capillaries, with the average interstitial distance roughly analogous to a capillary diameter. When an attempt is made to move the packed particles rapidly, a high shear resistance is encountered and the sediment behaves much like a hard, cement like mass and 
cannot be deformed, much less resuspended. This is because the particles are prevented from being rapidly displaced by the resistance to capillary flow.

As an example, consider a nonflocculated sediment in the bottom half of a beaker filled with water. A vigorous attempt is made to restir the sediment, but it is found to be unyielding and nonresuspendable. If, however, the stirring rod is left to rest on top of the sediment, the rod will slowly sink because the sediment behaves like a fluid. Moreover, if the beaker is slowly tilted, the sediment can be made to flow. In these cases, the applied shear is very small and the water can flow slowly through the capillary particle bed without the enormous pressure-drop resistance encountered during high shear. Capillary resistance will occur irrespective of the shape of the sedimented particles.

Another commonly cited example of this phenomenon is the ocean beach, where the wet sand near the water seems as hard as pavement when running along it (rapidly applied shear), yet fluid and deformable if stood on (slow shear).

\subsubsection{Morphological Effects}

In addition to capillary resistance to rapid shear by virtue of tight packing, the jayged edges of the comminuted (crushed) frits and $\mathrm{SiO}_{2}$ particles tend to interlock and contribute to the observed dilatancy (shear resistance) of frit sediments. The spheridization of frit particles would overcome this factor.

Also important is microscopic yeometric entanglement due to the morphological (surface roughness or texture) characteristics of most $\mathrm{SiO}_{2}$-containing particles. It is likely that the surfaces of frits and $\mathrm{SiO}_{2}$ particles are covered with needle-like projections that lock adjacent particles together on a microscopic level. If this is indeed the case with frits, spheridization may be of limited value since the needles will be present regardless of particle sphericity. Electron micrographs could be used to verify this hypothesized characteristic of frit/ $\mathrm{SiO}_{2}$ particle-surfaces.

\subsubsection{Solids Bridging}

If a sediment is allowed to sit long enough, perhaps months, interparticle bridging will probably occur due to the close proximity of the interlocking 
particles and the interpenetration of the needle-like projections. As with the related phenomenon of particle size disproportionation (discussed in Section 2.2.2), the driving force is the reduction of surface free energy when individual particles bridge together into clumps of smaller surface area. The rate of bridging increases with increasing particle solubility; increasing particle roughness (macroscopic and microscopic); and decreasing particle size. Particle bridging is a potentially major problem where sediment has remained for months or years at the bottom of nonflocculated nuclear waste tanks. Bridged tank solids will have to be broken up and crushed again or dissolved prior to processing.

\subsection{FLOCCULATED SEDIMENTATION}

Flocculated particles can form a sediment with a dramatically more favorable rheology. As seen in Figure 2, the irregularly shaped multiple-particle flocs do not pack well, and they form a loose, relatively voluminous sediment that in yeneral behaves like a Bingham plastic rather than as a dilatant (shear resistant), solid-like mass. (a) With a relatively small applied shear stress, a flocculated sediment can be resuspended into a homogeneous dispersion; thus lines can be more easily flushed; pumps can be replaced "on the fly"; and agitation can be resumed even after weeks or months. As with other Bingham plastics, the shear stress required to initially deform the flocculated sediment and induce fluidity is termed the "yield stress."

Flocculated particles form a resuspendable sediment mainly because small particles form irregular flocs and are thus prevented from tight packing. The interstices are larger than capillary dimensions, and capillary flow resistance is not encountered. Also, microscopic geometric entanglement is eliminated and the interlocking of comminuted (nonspherical) particles is reduced because they are separated. Spherical frit would prevent particle interlocking, but may not

(a) Small particles ( 10 microns) that flocculate may form regular spherical agglomerates that can still pack tightly and thus do not exhibit a favorable rheology. The shape and size of the flocs are therefore the determineiny factors as to whether resuspendability is achieved. 


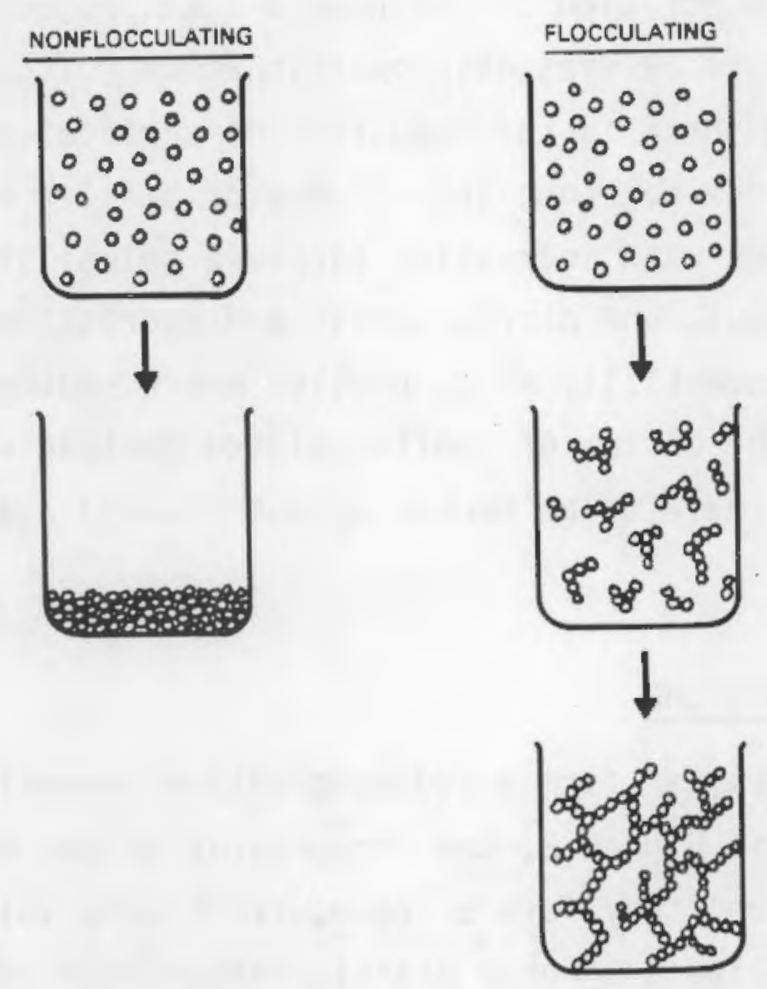

FIGURE 2. Sedimentation in Flocculating and Nonflocculating Systems

be warranted as the flocculated sediment rheology would suffice. Solids bridging, which occurs most rapidly when particles are tightly packed, would be greatly reduced or eliminated.

Comparison of a flocculated and nonflocculated sediment is shown in Figure 3. The tube on the left contains CAW/raw-chemical glass formers prepared only minutes before the photograph was taken; a hard, nonresuspendable sediment has already formed. The blurred interface indicates that some of the smaller particles are still settling and some ( $<10$ microns) have remained in suspension. The tube on the right is CAW/raw-chemical glass formers containing a flocculating agent, D1, (a) $2000 \mathrm{ppm}$ concentration, which was allowed to sit for about 4 days. (Figure 6 is another photographic comparison, this time with feed samples in 150-mL beakers.) The "sediment" formed with the aid of the

(a) Polymer tradenames have been deleted in this report to avoid the unfounded extension of the test results to other applications. A list of the polymers used in this research has been provided to the Department of Energy. 


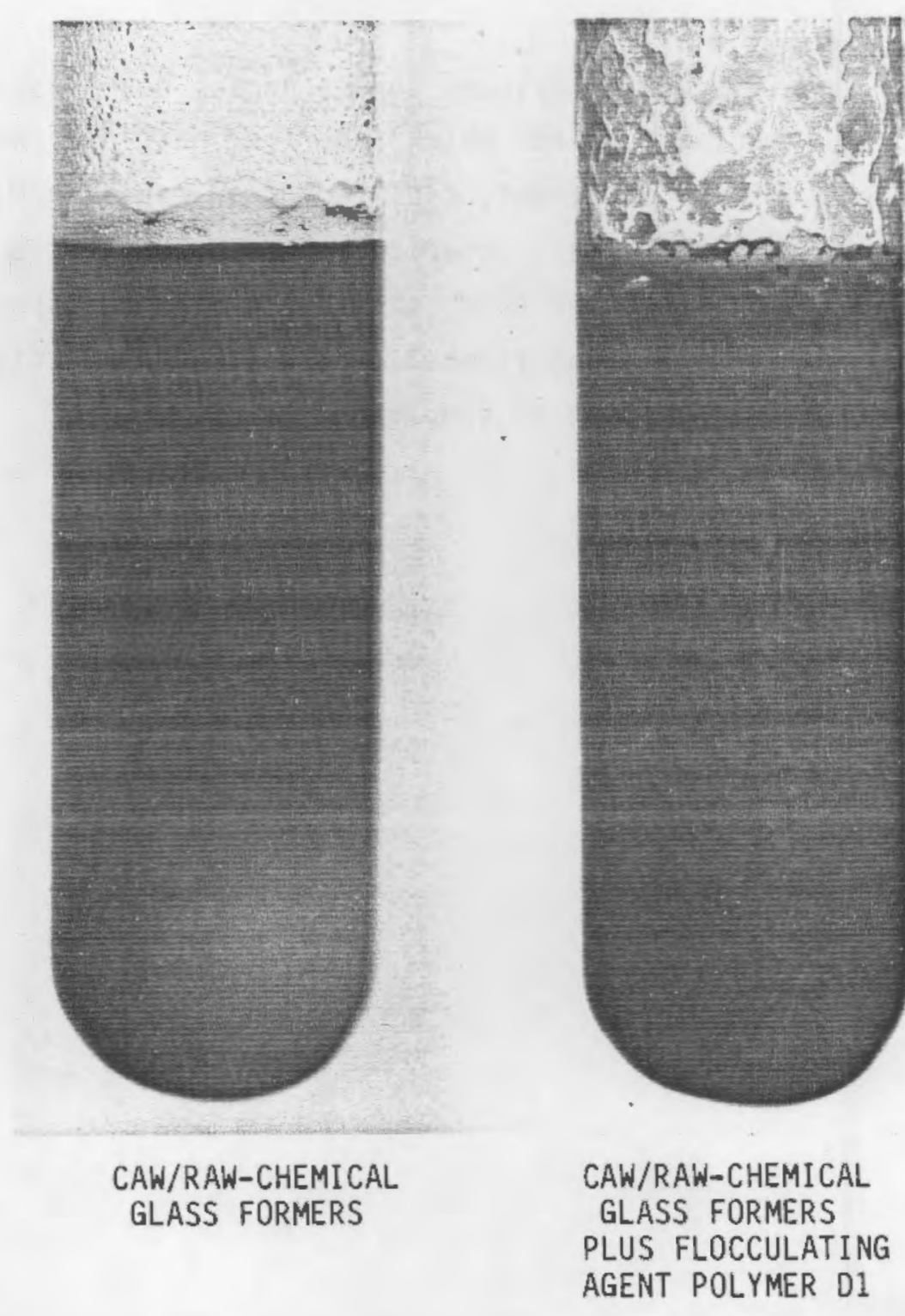

FIGURE 3. Sediment Volume Increase due to Addition of Polymer

flocculant is so voluminous that it occupies $295 \%$ of the slurry volume. This sediment is loose enough to be broken up and refluidized with minimal agitation even after weeks without agitation. Other polymeric flocculants (discussed later) did not result in as dramatic a volume increase, but all resulted in a resuspendable sediment whether frits or raw-chemical glass formers were used and irrespective of the type of simulated waste studied. 


\subsection{SUMMARY}

In summary, nonflocculated systems form a dense, nonresuspendable sediment through particles interlocking (for which spherical particles would be a cure) and through microscopic entanglement, capillary flow resistance and slow particle bridging, which would all occur regardless of particle sphericity. Flocculated systems, on the other hand, can form easily resuspendable sediments upon addition of small amounts of flocculating agent irrespective of the type of glass-former particle or type of simulated waste. 


\subsection{RESULTS: COLLOIDAL TECHNIQUES APPLIED TO SLURRY RHEOLOGY}

Colloidal techniques have been investigated and developed to improve the rheology of the Hanford CAW feed slurry and the West Valley acidic feed slurry. Most of the work was done to the Hanford CAW slurry because it exhibited the worst behavior and therefore required the most effort. The west valley slurry was fairly well behaved to start with, but some feed-chemistry optimization was performed.

Also discussed is an evaluation of the likeihood of slurry gellation-initially anticipated as a potentially serious problem in adding glass formers to acidic wastes. The study indicated that gellation would not be a problem with either Hanford CAW or West Valley wastes but might be one in processing other acidic wastes. An innovative method to prevent gellation was developed.

\subsection{HANFORD CURRENT ACID WASTE (CAW) RESEARCH}

Samples of Hanford CAW/glass former slurry prepared in the laboratory consistently exhibited worst-case sedimentation when left unagitated. The slurry particles settled within minutes and furned a hard, nonresuspendable sediment when Frit 82-10 was used as the glass former. This sediment was usually so difficult to resuspend (or even remove) that the glass sample containers could not be cleaned but were instead discarded. However, when rawchemical ylass formers were used rather than Frit 82-10, the sediment formed was easier to resuspend, but still not acceptable for transporting. Because of their better behavior, raw chemicals were chosen over Frit 82-10 as a first step in optimizing rheology. (a)

Three methods were successfully used to alter and allow control of the rheology of the CAW feed slurry: $\mathrm{SiO}_{2}$ particle size manipulation; $\mathrm{pH}$ manipulation; and polymer-induced flocculation. The impact of all three methods on waste processing is also discussed below.

(a) Unfortunately, the use of raw chemicals may be disadvantageous in radioactive waste glass-making because boron volatility increases when frits are not used. Further research is required to determine the extent of this effect. 


\subsubsection{Manipulation of Particle Size}

The substitution of a $49 \mathrm{wt} \% \mathrm{SiO}_{2}$ suspension with a $\sim 10$-micron particle size for raw-chemical $\mathrm{SiO}_{2}$ powder completely prevented sedimentation. This is to be expected since thermal agitation is enough to maintain individual particles of that size in suspension. In addition, when left unagitated, the CAW/colloidal silica forms a yel. As suggested by the discussion in Section 2.2.1, this gel consists of multiple particle flocs that are "crosslinked" and extend throughout the CAW resulting in a homogeneous (nonsedimenting) system. The flocculation is made possible by the lack of interparticle double layer repulsion since double layers are insignificant (or absent) in highly ionic solutions like CAW.

That the yel formed when CAW/colloidal silica is left unagitated can be easily refluidized was demonstrated using a peristaltic pump and a sparged plexiglass column. The CAW/colloidal silica was allowed to gel and left unayitated for 2 days in the $1 / 4 \mathrm{in}$. dianeter stainless steel input and output ines of the peristaltic pump. It was found that the gel within the pump lines was refluidized immediately following reactivation of the pump. Over the same time interval, $5 \mathrm{gal}$ of the feed was allowed to gel and remain unagitated in a 4 in. diameter air sparged plexiglass column. It was found that the gelled feed was rapidly refluidized with only minimal sparging. This procedure was repeated several times with the same result. The CAW/colloidal'silica feed is thus the ideal processing fluid, having no tendency to clog.

While acceptable as an $\mathrm{SiO}_{2}$ source in a simulated melter feed, the 49 wt\% $\mathrm{SiO}_{2}$ suspension may not be acceptable in a radioactive waste processing plant for the following three reasons.

First, the suspension contains $251 \%$ water and would thus dilute the waste stream, resulting in an increase in volatiles. Considerable effort is taken to eliminate excess water upstream since more volatiles means more off yas to contend with and in general, a slower melter feeding rate. In spite of this, at 
least two important vitrification processes(a) are considering adding glass formers in 50 wt\% slurry meaning that the use of 49 wt\% colloidal silica would not result in an increased dilution.

The second reason is that floc restructuring may occur under certain conditions. Deleterious floc restructuring has been observed during the use of an ultrasonic device with a sample of CAW/colloidal silica. At a certain ultrasonic energy level, the sample was found to change from a nonsedimenting to a rapidly sedimenting system. It is hypothesized that under these conditions, spherical rather than chain-shaped multiple particle flocs were formed, which would result in a significant reduction in surface/volume ratio. As discussed in Section 2.2.1, such a surface reduction can lead to the observed rapid sedimentation. Nonetheless, under no other conditions has floc restructuring been observed.

If floc restructuring and consequent sedimentation of the 10 -micron suspension did occur, the suspension may provide no more benefit than would be obtained using raw-chemical $\mathrm{SiO}_{2}$. This is because the 10-micron particles may be too small to form the large, irregular flocs required to form resuspendable sediments. Moreover, if the particles floc to form regularly shaped clumps, they may pack tightly and form interstices that are small enough to impose capillary flow resistance and thus form a shear-resistant, nonresuspendable sediment. This behavior would, if it occurs, be similar to the observed behavior of nonflocculated -325 mesh $\mathrm{SiO}_{2}$ sediments. Also, if tight packing occurs, microscopic interpenetration of needle-like protrusions at the surface of the $\mathrm{SiO}_{2}$ particles may cause them to stick together, thus further impeding resuspension.

Flocculation of colloidal silica can probably be prevented if the particles are sterically stabilized through the adsorption of polymers of intermediate molecular weight (between $10^{3}$ and $10^{4}$ ). The adsorbed polymers would create interparticle repuision through steric and/or enthalpic effects. Steric stabilization could probably prevent floc formation over all conceivable conditions. Also, colloidal silica concentrations greater than 49 wt\% could

(a) The HWVP and DWPF processes. 
definitely be achieved in this manner, thereby reducing feed dilution. of course, the colloidal silica suspension would have to be purchased pre-polymer stabilized or polymer-stabilized and then concentrated. Finally, it must be emphasized that colloidal silica floc restructuring has not been observed under normal feed processing conditions and may thus not be a problem.

Another perhaps less costly alternative would be to add 5-10\% of the required $\mathrm{SiO}_{2}$ as the 10 micron suspension and the rest as 400 mesh (37-micron particle size cut-off) raw chemical $\mathrm{SiO}_{2}$ or frit. If the colloidal silica were polymer treated so as to prevent flocculation, its presence in the feed may have a beneficial thickening effect. Research would, of course, be needed to verify this. If untreated, the 10 micron particles would almost certainly stick to the larger frit or raw chemical $\mathrm{SiO}_{2}$ particles, thus defeating their intended purpose.

The third reason that colloidal silica may not be a desirable $\mathrm{SiO}_{2}$ source is less easily overcome. Based on the melting of the CAW/colloidal silica feed in the pilot scale ceramic melter (PSCM), it appears that the presence of colloidal silica in the feed may reduce melting rates. This potential problem is described in Section 6.1 .

\subsubsection{Manipulation of Nitric Acid Concentration}

Incremental increases in $\mathrm{HNO}_{3}$ concentration above the reference $1.06 \mathrm{M}$ showed an optimum effect on the rheology of the CAW/raw-chenical glass-former slurry at around $1.35 \mathrm{M} \mathrm{HNO}_{3}$. The results of the incremental increases in $\mathrm{HNO}_{3}$ concentration are given in Table 4. As $\mathrm{HNO}_{3}$ concentration was increased, the resuspendability of the resulting sediment increased, probably due to the increasing hydration of particles. In a second study using finer increments than shown, the percent volume increase again reached an optimum at $1.35 \mathrm{M}$. Figure 4 comprises photographs of an array of CAW samples taken at time 0 , 5 minutes and 16 hours without stirring. $\mathrm{HNO}_{3}$ content increases to the right, as shown in Table 4, which gives the $\mathrm{HNO}_{3}$ content for each sample. Note that complete blanching of the slurry occurred at an $\mathrm{HNO}_{3}$ content of $6.8 \mathrm{M}$. The blanching may have been caused by the more complete oxidation (and dissolution) of the $\mathrm{Fe}^{3+}\left(\mathrm{NO}_{3}{ }^{-}\right)_{3}$ and $\mathrm{Fe}^{2+} \mathrm{NO}_{3}{ }^{-}$species, which were presumed responsible for the "root beer" color of the reference sample. 
TABLE 4. Effect of Nitric Acid Addition on CAW Slurry Sediment Volume

\begin{tabular}{llll}
$\frac{\mathrm{HNO}_{3}, \mathrm{M}}{0.67}$ & & \multicolumn{2}{c}{ Increase, vol\% } \\
\cline { 1 - 1 } 0.87 & & -4 & \\
1.26 & & 23 & \\
1.63 & & 34 & \\
2.59 & & 43 & easily \\
4.13 & 38 & resuspended \\
5.23 & 34 & \\
6.77 & 51 &
\end{tabular}

The increase in $\mathrm{HNO}_{3}$ concentration from 1.06 to $1.35 \mathrm{M}$, initially considered an untenable constraint on the vitrification process due to increased $\mathrm{NO}_{\mathrm{X}}$, was found quite manageable. The $\mathrm{HNO}_{3}$ content of Hanford CAW can be readily increased by decreasing the extent of the proposed "acid-kill" process. If this is done, it is recommended that some acceptable form of particle-size manipulation also be done, as previously discussed. The combination of increased $\mathrm{HNO}_{3}$ content and the sieving of all or part of the glass-former particles to 400 mesh ( $\leq 37$ microns) would probably result in an acceptable Hanford CAW feed.

\subsubsection{Polymer-Induced Flocculation}

In yeneral, a flocculated system forms a resuspendable sediment and is therefore inherently more desirable than a nonflocculated sedimenting system. In particular, this is true when the particle flocs are large and irregular and thus resist tight packing.

It has been found that the volume of sediment, and thus its resuspendability, even after days without agitation, can be greatly enhanced through the use of polymers. The polymer-bridged particle flocs are thus large and irregularly shaped. $D 1,(a)$ the polymer that performed best, can be used successfully with

(a) Polymer tradenames have been deleted in this report to avoid the unfounded extension of the test results to other applications. A list of the polymers used in the research has been provided to the Department of Energy. 

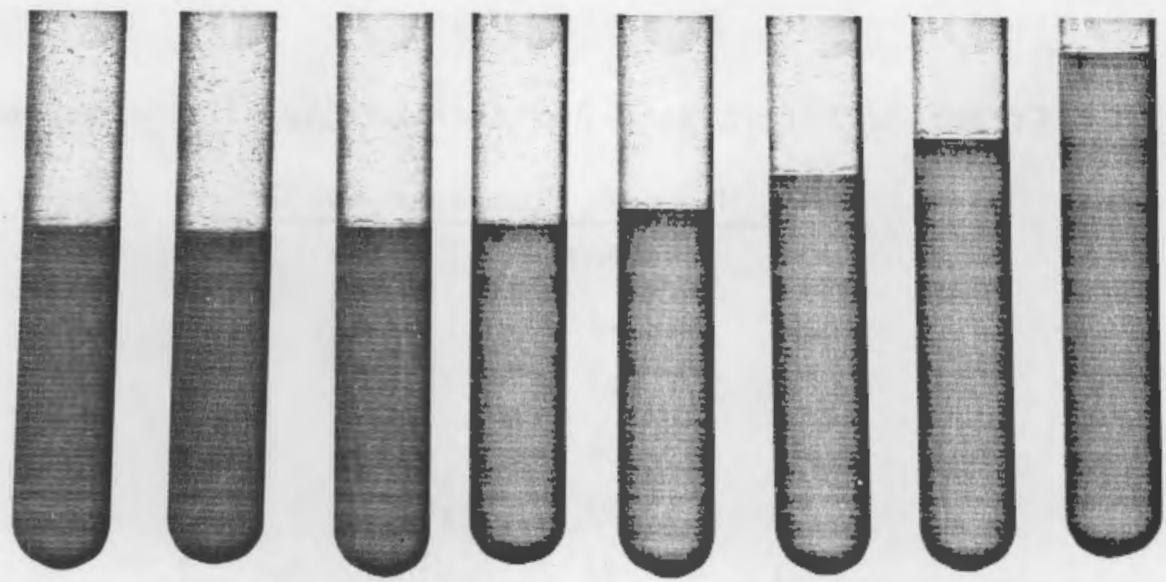

$\mathrm{HNO}_{3}, \mathrm{M}$

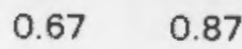

1.26

1.63

2.59

4.13

5.23

6.77

O MIN
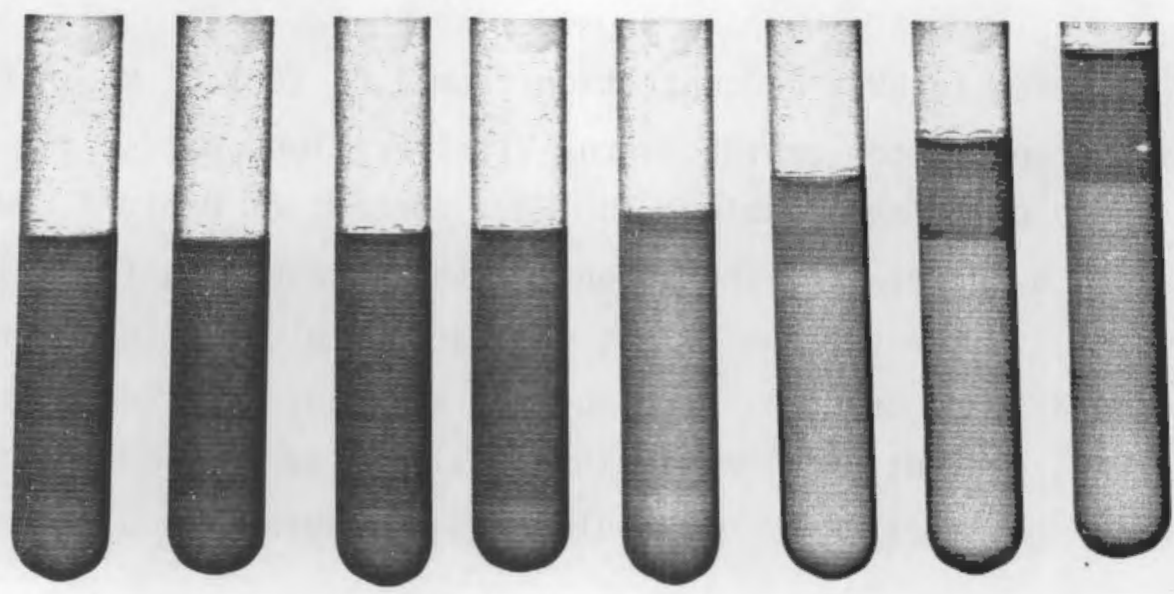

5 MIN
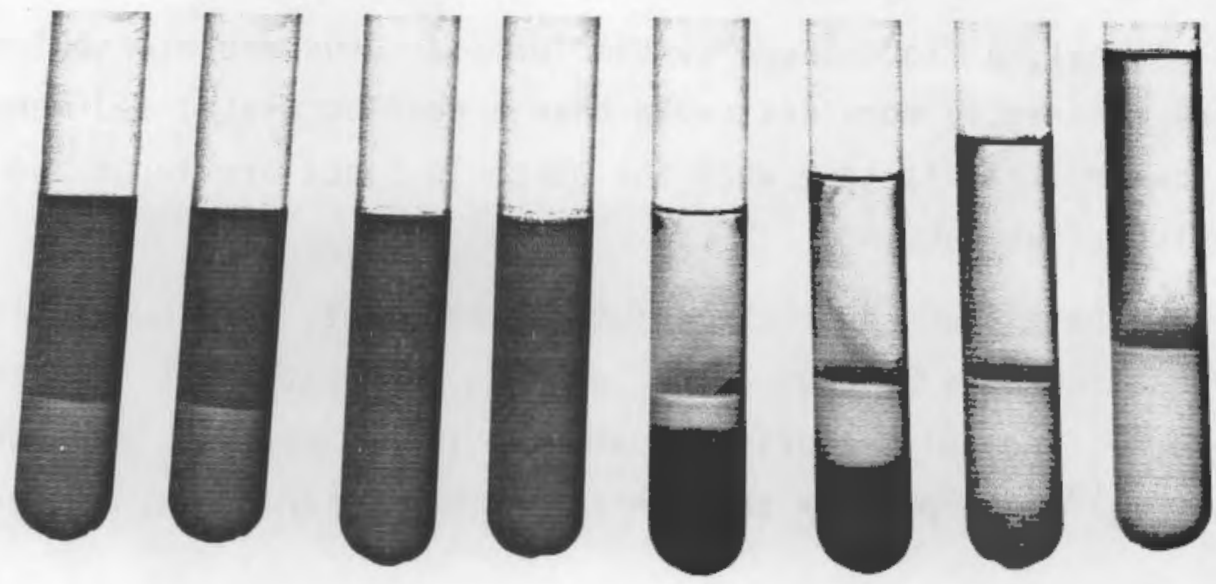

$16 \mathrm{HR}$

FIGURE 4. Effect of Nitric Acid Content on CAW Feed 
the CAW feed at concentrations of 1500 to $4000 \mathrm{ppm}$. Figure 5 compares the effects on sediment volume of adding various polymers to the CAW/raw-chemical glass-former slurry. Polymer D1 was found to maintain $29 \%$ of the raw-chemical glass formers in suspension virtually indefinitely and thus prevent all but $5 \%$ of the particles from settling out. In addition, the suspension remained fluid. Figure 6 is a photograph comparing the effect of polymeric addition on the sediment volume of CAW/raw-chemical glass former. To the right beaker has been added $2000 \mathrm{ppm}$ of polyacrylamide D1. These concentrations are based on the method of adding polymers in the laboratory. It may be possible to reduce the required polymer concentrations by up to an order of magnitude when the polymer is slurried with the glass formers before being pumped through the cell wall.

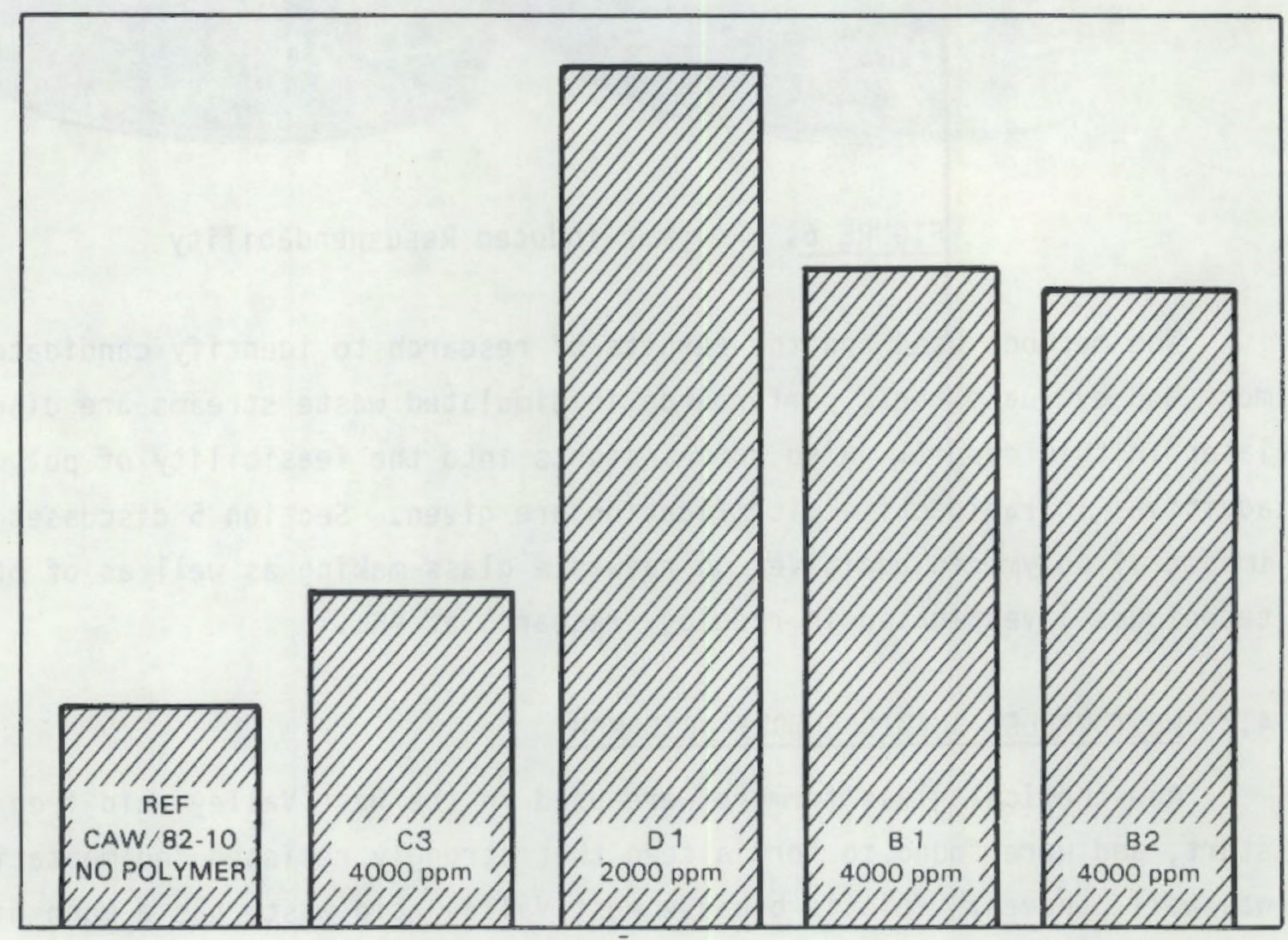

FIGURE 5. Polymer Effects on CAW Slurry Volume. (Sediment volumes shown are accurately scaled.) 

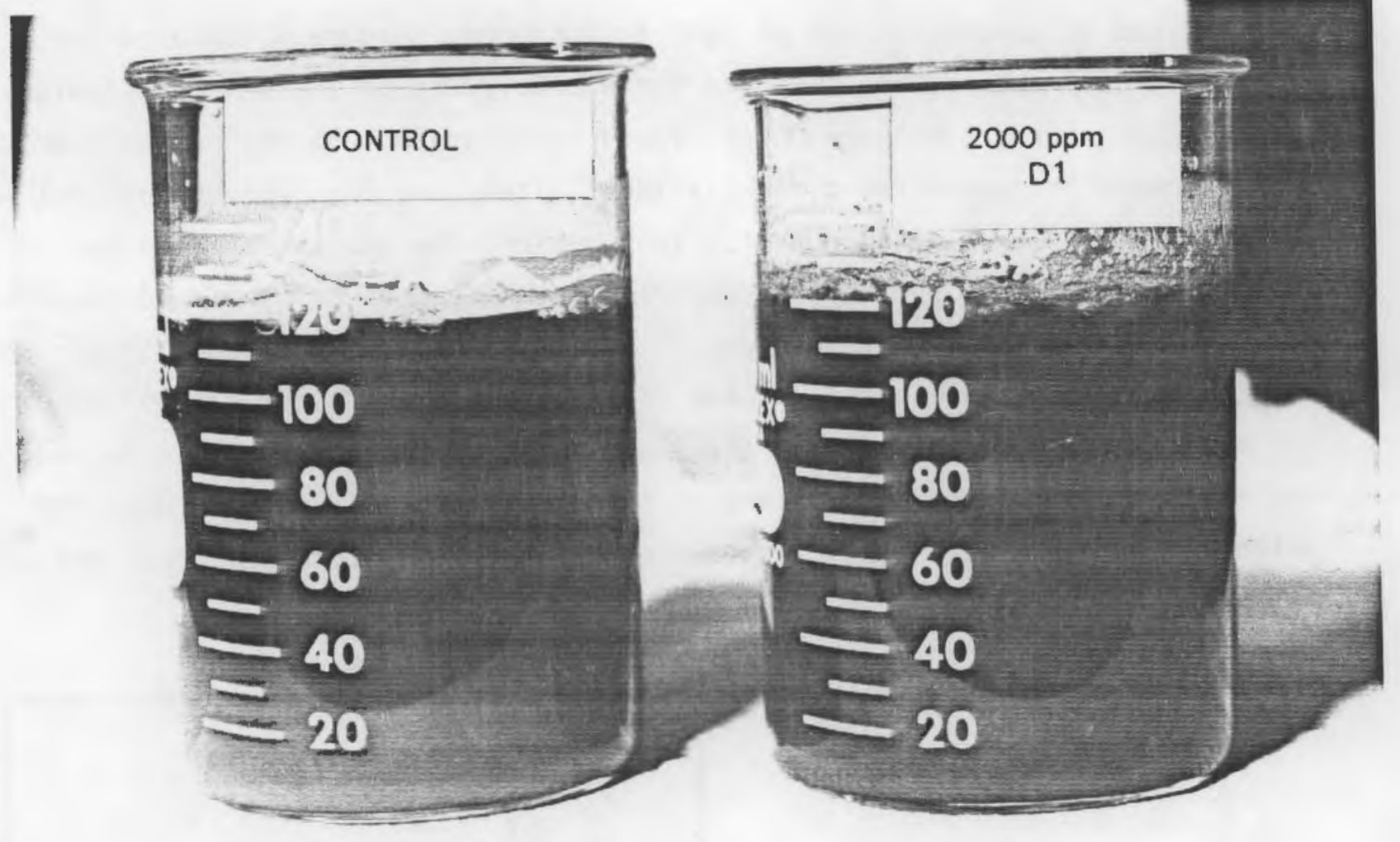

FIGURE 6. Polymer-Induced Resuspendability

The methods used and the results of research to identify candidate polymers and evaluate their performance in simulated waste streams are discussed later in this report. Also some insights into the feasibility of polymeric additives in radioactive vitrification are given. Section 5 discusses the impact of polymeric additives on radwaste glass-making as well as of other techniques investigated in rheology research at PNL.

\subsection{WEST VALLEY ACIDIC SLURRY RESEARCH}

Raw-chemical glass formers were used in the West valley acid feed from the start, and were found to form a feed that strongly resisted sedimentation and was well behaved. This is because West Valley acid waste has a much higher viscosity than wastes such as Hanford CAW ( 1000 cp versus $10 \mathrm{cp}$ ). (a) The high viscosity permits thermal agitation along with high-viscous drag to

(a) These are Brookefield viscosities at similar shear rates. 
maintain the $\leq 44-m i c r o n$ ( -325 mesh) $\mathrm{SiO}_{2}$ particles in suspension for a relatively long time. It is probable that the extremely slow settling rate allows loose flocs to form resulting in a very loose gel. This speculation is supported by the fact that even after several days, no sediment is formed indicating that settling has abated, and that the viscosity data displayed in Figure 8.3. in Appendix 8, indicates a.slight thixotropy as is exhibited by gels. Finally, in tests using a 4 in. diameter plexiglass column, feed samples taken at the bottom and top of the column (vertical distance of $\rightarrow$ feet) exhibited identical specific gravities to within an experimental error of \pm 0.01 . Other acidic me1ter wastes with viscosity on the order of $1000 \mathrm{cp}$ or greater could be expected to behave as favorably as the West valley acid waste/raw chemical glass former slurry. It is instructive to understand the general effect of viscosity on the rate of particle sedimentation by considering 5tokes' equation:

$$
v_{s}=\left(\frac{\Delta \rho g}{18}\right) \quad \mathbf{0}_{p}^{2} / n
$$

where:

$$
\begin{aligned}
& V_{S}=\text { particle sedimentation velocity } \\
& D_{p}=\text { mean particle diameter } \\
& n=\text { viscosity } \\
& g=\text { gravitational acceleration } \\
& \Delta \rho=\text { density difference between particle and solvent. }
\end{aligned}
$$

According to Stoke's equation for a slurry with a viscosity of 1000 CP (WVAW), $V_{S}=0.50 \mathrm{~cm} / \mathrm{hr}$ while for a slurry of $10 \mathrm{cp}$ (CAW), $V_{S}=50 \mathrm{~cm} / \mathrm{hr}$, with $\Delta p=1.0 \mathrm{~g} / \mathrm{cm}^{3}$ in both calculations.

While Stokes' equation is valid only for systems of much less ionic complexity and lower solids content than are associated with all melter feeds, its basic message is qualitatively correct in that high viscosity will prevent larger particles from settling rapidly. 


\subsection{FEED GELLATION RESEARCH}

One initial goal of the feed rheology research was to determine whether gellation of $\mathrm{SiO}_{2}$-based glass formers would occur in an acidic melter feed. The concern was that a very stiff, nonflowable gel might be formed either in the bottom or throughout a feed tank since $\mathrm{SiO}_{2}$ is known to be gel-forming.

As Table 5 indicates, this type of gellation could be induced only when an SRL frit (Frit-131) and West Valley acidic waste were mixed. The gel formed was a thick, solid-like mass exhibiting no fluidity that would almost certainly lead to clogging. Although that combination will never be used, it was feit that the potential for such difficulty exists and should be dealt with. The specificity of the gellation is hard to explain since, as shown in Table 6 , the three glass formers are similar in composition. However, only Frit-131 contains $\mathrm{TiO}_{2}$ and $\mathrm{La}_{2} \mathrm{O}_{3}$, and CAW and WVAW are fairly different, as can be seen in Appendix A.

TABLE 5. Slurry Gelling Behavior

$\begin{array}{lcccc}\text { SWVAW(a) } & \text { Frit-131 } & \frac{\text { Frit-164 }}{\text { Gelled }} & \text { No yel } & \frac{\begin{array}{l}\text { Raw-Chemical } \\ \text { Glass Formers }\end{array}}{\text { CAW }} \\ \text { No gel } & \text { No gel yel } & & \text { No gel }\end{array}$

(a) Simulated West Valley acid waste.

IABLE 6. Comparison of Glass-Former 0xide Compositions, wt\%

\begin{tabular}{|c|c|c|c|}
\hline & Frit-131 & Raw Chemicals & Frit-165 \\
\hline $\mathrm{SiO}_{2}$ & 57.9 & 61.7 & 68.0 \\
\hline $\mathrm{B}_{2} \mathrm{O}_{3}$ & 14.7 & 15.1 & 10.0 \\
\hline $\mathrm{Na}_{2} \mathrm{O}$ & 17.7 & 14.7 & 13.0 \\
\hline $\mathrm{Li}_{2} \mathrm{O}$ & 5.7 & 7.4 & 7.0 \\
\hline $\mathrm{MgO}$ & 2.0 & 1.1 & 1.0 \\
\hline $\mathrm{TiO}_{2}$ & 1.0 & 0.0 & 0.0 \\
\hline $\mathrm{La}_{2} \mathrm{O}_{3}$ & 0.5 & 0.0 & 0.0 \\
\hline $\mathrm{ZrU}_{2}$ & 0.5 & 0.0 & 1.0 \\
\hline
\end{tabular}


An innovative method was found to prevent gellation. An invention disclosure has been filed on the method; hence further details are omitted. Whether such stabilization can be relied upon to prevent adverse gellation in a problem feed can be established only by further research. 
.

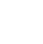




\subsection{GENERAL RESULTS OF POLYMER RESEARCH}

As discussed in Section 3.2, a flocculated system generally forms a resuspendable sediment and is therefore more desirable than a nonflocculated sedimenting system. Of course, a nonflocculating dispersion with no sedimentation at all is ideal, but such a dispersion is inherently unstable with respect to uncontrolled flocculation and/or sedimentation. For this reason, controlled flocculation and sedimentation is preferable.

\subsection{SUMMARY}

The factors that resist flocculation are thermal agitation, electrical double-layer overlap, and steric stabilization brought about by adsorbed molecules. Temperature-dependent thermal agitation only weakly resists the flocculation of frit and $\mathrm{SiO}_{2}$ particle sizes of interest, and feed absolute temperature is not a process variable. Electric double-layer overlap (electrostatic repulsion) can prevent flocculation, but the extent of overlap depends on the ionic strengths and valencies of the solvent. Since melter feeds are strongly ionic and contain high concentrations of trivalent gegenions, double-layer overlap is insignificant.

High-molecular-weight polymers in certain concentration ranges (usually 1000 to $4000 \mathrm{ppm}$ ) lead to a more resuspendable slurry sediment. In addition, bridging flocculation brought about by polymers is of greater benefit than spontaneous flocculation, as seen in Figure 7, which compares the three types of sedimentation. Polymer-bridged particles pack even less tightly than other flocculated particles and result in a sediment substantially more voluminous (less dense) and more resuspendable. Figures 3 and 6 are photographs comparing the effect of the most successful polymer additive on the sediment volume of CAW/chemical glass former melter. To the right-hand containers have been added 2000 ppm of polyacrylamide Dl. 

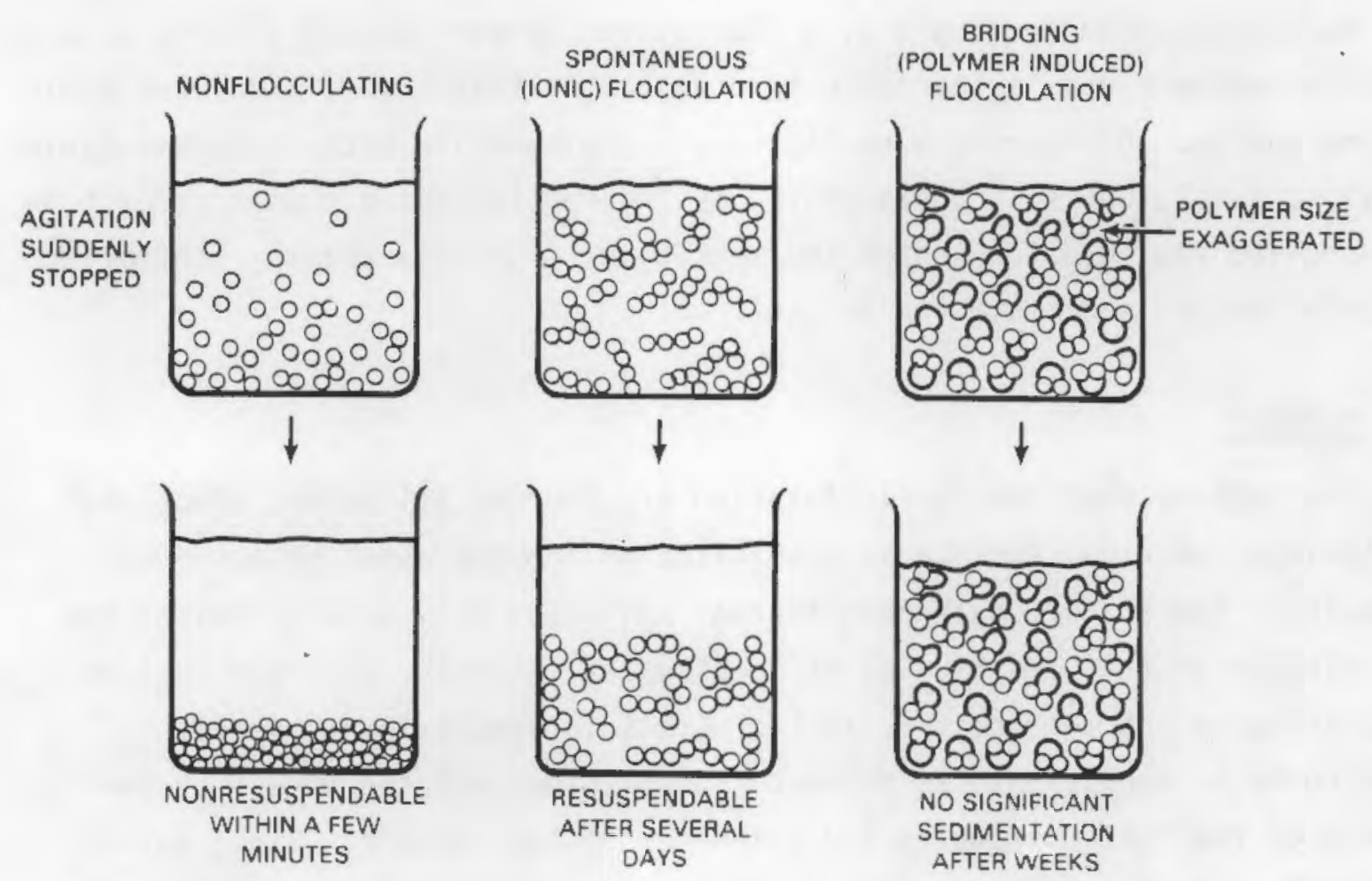

FIGURE 7. Comparison of Sedimentation Processes: Nonflocculating, Spontaneous Flocculation, Polymer-Induced Bridging Flocculation

\subsection{DESCRIPTION OF POLYMERS INVESTIGATED}

The polymeric flocculants that have had the most success in industrial applications are polyelectrolytes (Figure 8). These, as their name suggests, are polymers with ionizable functional groups in the structural repeating unit. The most common polyelectrolytes are polyacrylamides. High-molecular-weight ( 3 to 5 million) acrylamide polymers have found widespread application as flocculating agents even in the nuclear industry, where they have "revolutionized uranium hydrometallurgy by making hitherto extremely difficult liquid-solids separations both possible and economical."(a)

(a) From the Encyclopedia of Polymer Science and Technology, Vol. 8, p. 806. 
NON-IONIC

\begin{tabular}{|c|c|c|c|}
\hline REPEATING UNIT & NAME & IDENTIFIER & $\begin{array}{c}\text { RANGE } \\
\text { OF MOLECULAR } \\
\text { WEIGHT } \\
\end{array}$ \\
\hline$-(c-c-0) \bar{x}$ & $\begin{array}{l}\text { POLY(ETHYLENE } \\
\text { OXIDE) }\end{array}$ & A & $1 \cdot 5000$ \\
\hline
\end{tabular}

POLYELECTROLYTES

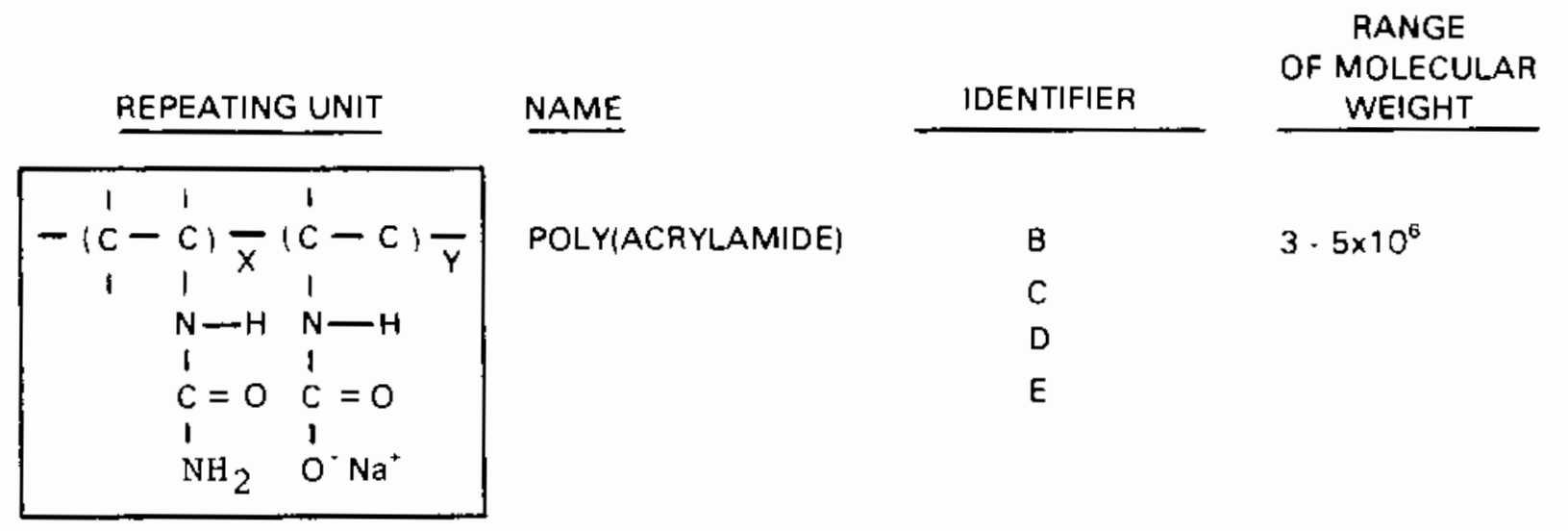

FIGURE 8. Polymer Structure

Although Figure 8 shows that some of the amide groups are usually hydrolyzed to anionic carboxyl groups, it is likely that in CAW all ionization will be suppressed by the strong acid environment. Further, the polymers will not function in any electrostatic capacity due to CAW's high ionic concentration, which will inhibit any electric double-layer repulsion between polymer repeating units. This means that polymer adsorption will proceed in ways that are not affected by the electrolytic concentration of the environment, but rather through chemisorption.

\subsection{METHDD AND RESULTS}

To determine whether or not polymers can enhance resuspendability of the CAW slurry sediment, a wide spectrum of polymer samples were obtained from 
various companies. These polymers were added, in different concentrations, to various liquids $\left(\mathrm{H}_{2} \mathrm{O}, 2 \mathrm{M} \mathrm{HNO} \mathrm{H}_{3}\right.$, dilute $\mathrm{CAW}$, reference $\left.\mathrm{CAW}\right)$, and the resulting solution was added to solid, dry frit. The resulting volumes of sediment, obtained from standardized samples after certain periods of settling time, were compared to determine what polymers affected the settling particles most strongly. In addition, qualitative tests were performed that gauged the ease with which sediment could be restirred. Tests were performed with both $\mathrm{H}_{2} \mathrm{O}$ and $2 \mathrm{M} \mathrm{HNO}_{3}$ as continuous phases when simulated waste was unavailable. Tests were also performed with dilute CAW before the reference CAW was available. (In all other sections of this report, only actual reference CAW is discussed.)

Although sediment volume increase is a quantitative test of polymer effectiveness, the most important behavior to report, with respect to the problem at hand, is the ease of resuspendability of the sediment. It was found that the $B$ and $D$ polyacrilymides made the sediment easily resuspendable even after a week of settling. Often the sediment volume decreased over this time, but the resuspendability of all samples was excellent compared to the unaltered slurry sediment .

\subsubsection{Polyethylene 0xides}

The polyethylene oxide polymers tested were found to be ineffective in altering the volume of slurry sediment in water, and they actually decreased the sediment volume in dilute CAW. Their lack of performance can be traced to the low molecular weight of the polymers. Based on their poor performance in dilute CAW, these polymers were not further tested in reference CAW.

\section{3 .2 Polyelectrolytes E}

Eleven polyelectrolytes in group $E$ were the first ones studied. These polymers yielded a promising sediment volume expansion when added to $\mathrm{H}_{2} \mathrm{O} / \mathrm{frit}$ systems. However, when CAW/frit systems were studied, they showed no tendency to increase the volume of the sediment. The molecular weights of these polyelectrolytes are unknown.

\subsubsection{Polyelectrolytes C}

Next to be studied were the $C$ polyelectrolytes. Four gave promising results with dilute CAW/frit systems: C4 showed a $17 \%$ sediment volume increase 
after 1 day of settling, C6 a 26\% increase, C8 a 35\% increase, and C3 a $22 \%$ increase. In addition, reference CAW/frit systems with polymers $C 3$ and $C 8$ were studied. Sediment volumes were greater in the reference CAW as compared to dilute CAW tests. $C 3$ and C8 exhibited maximum volume increases of $53 \%$ and $27 \%$, respectively.

\subsubsection{Polyelectrolytes B}

Based on the success of polyelectrolytes in the $C$ group, further research on sediment alteration was performed using polymers identified as B. All three of the $B$ polymers exhibited remarkable ability to increase the sediment volume in the dilute CAW/Frit 82-10 system. In addition, B2 kept the volume at very high levels (greater than $50 \%$ sediment volume increase) for long periods ( 3 days). The $B$ polymers provided excellent resuspendability because they induce loose packing in the sediment.

In addition to the three $B$ polymers tested in dilute CAW/frit systems (B1, B2 and B3), B4, was studied with reference CAW/frit systems. Of these four polymers, three showed excellent results. B1, B2 and B4 exhibited maximum sediment volume increases of $195 \%, 187 \%$, and $160 \%$, respectively.

\subsubsection{Polyelectrolytes D}

Finally, D polymers were studied. All five of those tested exhibited remarkable effectiveness in increasing the volume, and thus resuspendability, of the sediment. The $D$ polymers provided the largest sediment volume of the dilute CAW/frit systems observed. Next, reference CAW/frit systems were studied, resulting again in the largest sedinent volumes observed. In the best case, D1, at a concentration of 2000 ppm in reference CAW, provided a volume increase (after 1 day of settling) of $284 \%$. The suspended flocs extended throughout at least $90 \%$ of the slurry volume. This sediment was extremely loose and restirrable.

\subsection{EFFECT OF NITRIC ACID CONCENTRATION ON POLYMER STABILIZATION}

To determine the response of polymers to increasingly acid environtnents, experiments were performed in which a polymer's enhancement of slurry sediment volume was determined as a function of $\mathrm{HNO}_{3}$ concentration. The reference CAW/ 
frit slurry was used as a basis, with $2000 \mathrm{ppm}$ of $\mathrm{Dl}$ polymer added. Increnents of $\mathrm{HNO}_{3}$ were added directly to the slurry, then mixed. Table 7 lists the results and indicates that the maximum effectiveness of the polymer occurs at the reference CAW acid concentration. As the slurry becomes more acidic, the polymer becomes less effective as a sediment-volume modifier. It should be noted, however, that even though sediment volumes decreased at higher acid concentrations, resuspendability was still very good. Resuspendability at lower sediment volumes can probably be attributed to the effect of acid on the frit, such as was observed when performing acid scans of the CAW/frit system without polymers. In addition, different $D 1$ concentrations or different polyelectrolytes may be more effective at higher $\mathrm{HNO}_{3}$ concentrations.

\section{TABLE 7. Acid Concentration Dependence of DI (Reference CAW/Frit 82-10 System, $2000 \mathrm{ppm}$ 01)}

\begin{tabular}{lc}
$\mathrm{HNO}_{3}, \mathrm{M}$ & $\begin{array}{c}\text { \% Volume Increase in } \\
\text { Sediment Relative to } \\
\text { Polymer-free } 1.06 \mathrm{M} \mathrm{HNO} \\
\text { Slurry (1 day) }\end{array}$ \\
\hline 1.06 (Reference) & 222 \\
1.35 & 124 \\
2.14 & 53 \\
3.15 & 36
\end{tabular}

\subsection{EFFECT OF METHOD OF POLYMER ADDITION ON STABILIZATION}

In laboratory tests the fastest and most accurate way to construct a polymer/CAW/frit system is to add the CAW/polymer solution to a premeasured amount of frit. This is not, however, the way additions would be made in hotcell operation. Instead, a slurry of water and frit (or glass formers) would be fed through the cell wall and into a CAW stream. The polymers would thus be added to the water/frit slurry first. Conceivably, this different method could alter the polymer's effectiveness compared to the results in laboratory tests. This change could be brought about by aberrations in polymer adsorption due to the different environment $\left(\mathrm{H}_{2} \mathrm{D}\right.$ continuous phase) and solids concentrations encountered. 
Experiments were performed in which $2000 \mathrm{ppm} 01$ was added directly to a water/frit slurry, and the resulting slurry was then added to reference CAw. The results of this test were not as impressive as with other orders of addition, but it still is apparent that adding polymers to water/frit slurries which are then added to the waste stream will result in a modified slurry with greatly enhanced sediment resuspendability. It is probable that the 01 polymer added this way but at lower concentrations would be more effective than indicated in this test. 


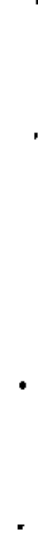




\subsection{IMPACT OF COLLOIDAL TECHNIQUES ON RADIOACTIVE WASTE GLASS-MAKING}

The quality of the vitrified waste product depends mainly on bulk properties of the molten glass, and the production capacity of the melter depends largely on the surface properties of the melt.

\subsection{COLD-CAP PROPERTIES}

Process feed enters the melter from a nozzle in the ceiling of the melting cavity. During normal operation, the nonvolatiles form a crust, or cold cap, at the surface of the melt. The cold cap is the intermediate stage between the feed nonvolatiles and molten glass. It is possible that methods used to modify the rheology of melter feeds may alter the melting rate of the cold cap and thus affect the melter's operating capacity.

It has been observed(a) that the $\sim 10$-micron $\mathrm{SiO}_{2}$ suspension may cause glass-making difficulties. The 10 -micron suspension would be a problem if severe aggregation and bridging of particles (incomplete meiting) occurred at the melt surface, forming a tough, themally insulative layer on top. Labscale dessication and melting studies, however, indicate that a cold cap formed with $\sim 1 \mathrm{D}-m i c r o n \mathrm{SiO}_{2}$ is powdery rather than aggregated, and visual observations made during the run tended to corroborate this. Despite its fragile appearance, the powdery cold cap may behave as a stable thermally insulative layer that diminishes melting rates. The evidence is thus far inconclusive.

\subsection{MELT FOAMING}

Foaming of the melt sometimes occurs but is avoided as it lowers the production capacity of a melter. The formation of bubbles within the molten glass probably has more than one source, and, since it is not currently well understood and thus difficult to predict what factors cause foaming, it is possible that methods of modifying the rheology of melter feeds may affect foaming. Some research has been directed toward identifying feed additives that may affect melt foaming.

(a) Experiments conducted by H. T. Blair and J. M. Perez, PNL. 
To evaluate possible foaming of CAW feed during melting, feed samples, representing the various alternative colloidal techniques investigated were prepared, dessicated, melted and evaluated for foaming. Sample foaming was evaluated by estimating the amount of glass remaining in the bottom of the crucible and thus inferring the amount lost from foaming. Although the tests were far from conclusive, general trends were observed. The samples tested were in order of increasing foaming:

CAW/raw chemical-glass formers

CAW/Frit 82-10

CAW/raw-chemical glass former/polymer Dl

CAW/Frit 82-10/polymer 01

CAw/raw-chemical glass former/49 wt\% $\mathrm{SiO}_{2}$ suspension ( $51 \%$ water) containing $\sim 10$-micron $\mathrm{SiO}_{2}$ particles.

To attempt to relate the crucible test results to melter-scale foaming, a sample of West valley acid feed was tested. The West Valley sample foamed less (in a crucible) than any of the CAW samples tested. This suggested that the CAw/raw-chemical glass former/49 wt\% $\mathrm{SiO}_{2}$ slurry, which was fed to the pilotscale ceramic melter (PSCM) in September 1983, would produce a melt with yreater foaming tendency than had been observed in Auyust 1983 during the West valley test.

During the Hanford run, however, foaming was not a problem, even though the feed had been identified as a worst-case foamer in the crucible tests. This suggests that neither the substitution of the $10-m i c r o n ~ \mathrm{SiO}_{2}$ slurry for other $\mathrm{SiO}_{2}$ nor the addition of polymer would alone cause foaning problems. Further research would be required for more definite conclusions.

\subsection{GLASS-REDUCING EFFECTS}

The quality of the vitrified waste product depends on its homogeneity, which can be diminished if heavy metal phases form within the molten glass and settle to the floor of the melting cavity. The heavy metals are formed by the reduction of metal oxides in the glass that occurs when reducing agents, e.g., carbon sources, are present in the molten glass. 
Organic (carbon-containing) polymers may reduce the metal oxides present in molten glass during vitrification, assuming the organic material is not volatilized while contained in the cold cap. The magnitude of metal oxide reduction would depend on the carbon content of the feed stream, implying a maximum acceptable organics content in the feed stream. It is difficult to determine the weight percent associated with the tentatively recommended polymer loading of $2000 \mathrm{ppm}$ since the molecular weight of the polymer itself is not well defined. Research is needed to determine whether a polymer loading of $2000 \mathrm{ppm}$ has a detectable effect on glass-making in a meiter. In the event of a polymer-induced problem of glass reduction, it is likely that the polymer loading can be reduced, through unsophisticated techniques, to as low as $200 \mathrm{ppm}$.

\subsection{BORON VOLATILITY}

Boron, which is an essential constituent of the glass product, is volatile to a certain extent, and the form of the boron source affects the volatility of boron. It has been shown (a) that combining boron species in a frit makes boron less volatile and thus more likely than raw-chemical boron sources such as $\mathrm{Na}_{2} \mathrm{~B}_{4} \mathrm{O}_{7}$ to remain in the glass phase. Since the boron content of a glass is crucial to the glass product's overall stability (and also to glass making), and since boron in the off-gas system is undesirable, it may be determined that glass formers, especially boron, must be fritted and not added separately.

Two methods of overcoming the rheological problems of fritted glass formers which maintain their advantageously low boron volatility are as follows:

- Combine all of the $\mathrm{Na}_{2} \mathrm{~B}_{4} \mathrm{O}_{7}$ with some of the $\mathrm{SiO}_{2}$ to form a frit of high boron content. The remainder of the glass formers required can then be added as raw chemicals, including a small amount of $\sim 10$ micron $\mathrm{SiO}_{2}$ suspension that has been treated with low MW polymers to prevent flocculation. The rheology would be improved over that of a complete frit, but to what extent would need to be determined.

(a) Experiments conducted by G. B. Mellinger, PNL. 
- Mix a small amount of high MW polymer ( 2000 ppm or less) with the usual frit (contained in the gallery make-up vessel) before adding the frit suspension to the waste. This method should make the melter feed transportable and could be implemented with equal success in neutralized or acidic wastes las discussed elsewhere in this report). 


\subsection{PROCESSING WITH POLYMERS}

In a process to vitrify radioactive waste, the polymers would be added to the gallery glass-former slurry make-up vessel, then pumped with the glassformer slurry to the feed make-up tank. There the glass-former slurry would be mixed with the high-level waste stream and would be present in the feed stream from the feed make-up tank to the melter nozzle.

\subsection{METHOD OF ADDING POLYMER}

The likely method of preparing the glass-former slurry would be to first add either frit or raw chemical $\mathrm{SiO}_{2}$ to the mixing vessel, then high $\mathrm{MW}$ polymer for bridging flocculation and finally the remaining soluble raw chemical glassformer constituents (if frits are not used). If colloidal $\mathrm{SiO}_{2}$ is to be used, it must be pretreated with low MW polymer. The amount of water charged initially to the mixing vessel could probably be minimized to avoid excessive dilution of the feed stream.

\subsection{SOLIDS LOADING IN GLASS-FORMER STREAM}

Laboratory experiments to measure the increase in feed slurry viscosity with increasing glass-former content imply that a much higher than suspected solids loading can be achieved. Figure B.5 in Appendix B displays the experimental data as a function of shear rate for the West valley acid feed. At a viscometer spindle speed of $60 \mathrm{rpm}$ (moderate shear rate), WVAW feed with solids higher than $900 \mathrm{~g} / \mathrm{L}$ displayed a relatively small viscosity increase of 300 to 1300 centipoise. The viscosities at these loadings remained below the viscosity measured at $6 \mathrm{rpm}$ (very low shear rate) for a solids loading of only $100 \mathrm{~g} / \mathrm{L}$.

Extrapolation of the test data suggests that glass-former loadings greater than $1000 \mathrm{~g} / \mathrm{L}$ might be achievable. Further, the addition of polymers is reported in the literature to lower slurry viscosity. Thus, with the added benefit of polymer-induced improvement of viscosity, it is possible that the 
glass-former soljds loading can be maintained as high as $1500 \mathrm{~g} / \mathrm{L}$ or more. clearly, further experimentation would be required to establish upper limits for solids loading.

\subsection{IMPACT ON CONSTRAINTS IN EQUIPMENT DESIGN}

In recent years, major emphasis has been placed on advanced equipment design as a means to overcome the historical melter feeding difficulties-clogging, pump wear and poor agitation. The goal has been and continues to be the design of a transport system that will adequately handie feed slurries. Thus far this approach has met with only partial success.

With a polymer-stabilized feed stream, the constraints on design and operation of transport equipment are significantly reduced. Pump design is made less critical for several reasons. First, the required pump lifetime is no longer crucial since a failed pump can be replaced at any time, up to weeks after the failure is detected. This is due to the resuspendability of the altered feed. After a new pump is installed, operation is resumed and the polymer-altered feed is refluidized. Second, the buildup of solids in dead spots will be minimal since the altered feed does not form clogs. In a clogforming slurry, dead spots act as clog "nucleation" sites where dilatant sediment can grow and eventually block check valves and orifices. Line, valve and T-connection geometries are no longer prohibitive for the same basic reasons. With an essentially nonsedimentary slurry, line flushing may not even be needed, unless calcination of the feed occurs in the feed nozzle. Finally, the extent of agitation in the feed make-up vessel would not be as crucial. Even if agitation were lost for weeks, the slurry could probably be refluidized and suspended. A transport systen could survive major breakdown and replacement of a component and be restarted without difficulty. Thus, it is likely that existing standard hardware could be used in-cell to transport rheologically altered feed slurry.

The situation described above is similar to that faced in well-drilling operations. In well-drilling, a drilling mud is used that pumps smoothly but which, upon pump breakdown, forms a gel. The gel maintains the mud particles as well as metal shavings in suspension until the inoperative pump is 
convenientiy repaired or replaced. Pumping is then resumed. The well-drilling mud rheology is tailored using the colloidal technique of ionic stabilization as described by electrical double-layer repulsion in Section 2.3.3. (As discussed in that section, ionic stabilization cannot be used with melter feeds.)

\subsection{IMPACT ON PROCESS QUALITY CONTROL}

By ensuring that all melter feeds are stabilized through polymer adsorption, settling solids can be eliminated. Because a stabilized slurry can maintain relatively large particles ( $\leq 1 / 4 \mathrm{in}$. dia, for example) in suspension, large particles in the waste stream are less likely to be "lost" in transportsystem dead spots or in the bottom of the feed make-up vessel. Hence, wastestream mass accountability might be more realizable when the transport medium possesses superior rheology. As an example, both nonsophisticated equipment and procedures could be employed for sampling the feed make-up tank. More importantly, a nonsedimenting feed is more nearly homogeneous throughout the feed tank so that the composition of the feed leaving the tank is constant.

\subsection{POLYMER SURVIVABILITY}

There is reason to believe that polymers will retain their effectiveness in a radioactive stream; FY 1984 research is being undertaken to ascertain this.

Undoubtedly, radiation will break polymer chains, which may or may not affect slurry stability. However, since the primary polymer adsorption will occur in the gallery glass-former mixing vessel, and since desorption of polymer, even in radiation, should not occur, some degree of stabilization will be present in any case.

Hence, if radiation-induced degradation occurs, it may not affect the polymer stabilization.

\subsection{UNIVERSAL APPLICABILITY OF POLYMERS}

Because of polymers' relatively high immunity to $\mathrm{pH}$ and ionic concentration, polymeric stabilization can be applied to virtualiy any stream with 
similar results. In addition, either frits or raw chemicals can be used as glass formers. Polymeric stabilization is the only current method of creating flowable melter feeds when frits are referenced.

For this reason, once polymeric stabilization has been demonstrated feasible for one radioactive stream, it will have been verified as a potential means to stabilize other high-level waste slurries. Of course, candidate polymers must be screened for each stream to find the best combination of polymers and polymer concentration. Transport system design would then become far less problematic than it has been heretofore.

\subsection{RECOMMENDED RELATED RESEARCH}

The following outlines suggested further research:

- Prevention of feed caking (drying and scale formation) at air/feed interfaces, particularly in the air disengagement chamber of airlift systems.

- Characterization of the rheology of other waste streams, e.g., spent resin and/or zeolite.

- Determination of maximum glass-former solids loading in glass-former add 1 ine to minimize feed dilution.

- Characterization of existing Hanford tank sediments.

- Methods of adding polymers to a melter feed stream.

- Determination of worst-case impact of polymers on glass formation in polymer ranges of 2000 to $8000 \mathrm{ppm}$.

- Effect of electroviscosity (when $\sim 10-m i c r o n, 49$ wt\% $\mathrm{SiO}_{2}$ suspension is used as a glass former) on pump and line sizing criteria.

- Empirical development of turbulent flow criteria for the glass former slurry and feed slurry sample line sizing.

- Concentration of waste solids in a settling chamber via polymer bridging flocculation. 
- Determination of slurry side heat-transfer coefficients to aid in establishing criteria for vessel cooling hardware.

- Identification and testing of powder-dispersing agents (surfactants) to provide better mixing of simulated wastes, chemicals and rawchemical glass formers.

- Effectiveness of spherical frit on feed rheology.

- Further research on manipulation of frit particle size.

- Further development of high-boron-content partial frit.

- Characterization of colloidal silica flocculation conditions.

- Development of quantitative methods for rheology characterization.

- Screening of polymers not used in present work. 


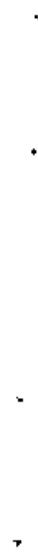




\subsection{BIBLIOGRAPHY}

Adanson, A. W. 1982. Physical Chemistry of Surfaces, 4th Ed.. Wiley Interscience.

Berg, J. C. 1981. Short Course on Surface and Colloid Science. University of Washington, SeattTe, washington.

Denn, M. M. 1980. Process Fluid Mechanics. Prentice-Hall.

Holland, F. A. 1966. Liquid Mixing and Processing in Stirred Tanks. Reinhold.

Iler, R. K. 1979. The Chemistry of Silica. Wiley Interscience.

Lapedes, I., ed. 1978. Dictionary of Scientific and Technical Terms, 2nd Ed. McGraw-Hill.

Larson, D. E., J. L. Buelt, W. 0. Heath, and W. L. Partain. 1983. Assessment of Power Reactor Waste Immobilization by Vitrification. EPRI NP- 3225 , Electric Power Research Institute.

Linke, W. F. et al. 1960. "Physical Chemical Aspects of Flocculation by Polymers." Am. Inst. Mining. 217.

Matijevic, E., ed. 1976. Surface and Colloid Science, vol. 9. Wiley Interscience.

Napper, D. H. 1970. "Steric Stabilization." Journal of Colloid and Interface Science $32: 106$.

Ottewall, R. H. 1977. "Stability and Instability in Disperse Systems." Journal of colloid and Interface Science $58(2)$.

Overbeek, J. Th.G. 1977. "Recent Developments in the Understanding of Colloid Stability." Journal of Colloid and Interface Science 58(2).

Perez, J. M., Jr. 1983. Design and Performance of Feed Delivery Systems for Simulated Radioactive Waste Slurries. PNL-4423, Pacific Northwest Laboratory, Richland, Washington.

Perry, R. H. and C. H. Chilton et al. 1973. Chemical Engineers' Handbook, 5th Ed. McGraw-Hill.

Quigley, M. S. and D. K. Kreid. 1979. Physical Modeling of Joule Heated Ceramic Glass Meiters for High Level Waste Immobilization. PNL-2809, Pacific Northwest Laboratory, Richland, Washington. 
Shaw, D. J. 1980. Introduction to Colloid and Surface Chemistry, 3rd Ed. Butterworths.

Van 0lphen, H. 1977. Clay Colloid Chemistry. Wiley Interscience. 
APPENDIX A

COMPOSITION DF CAW AND WEST VALLEY ACID FEEDS 


\section{APPENDIX A}

\section{COMPOSITION OF CAW AND WEST VALLEY ACID FEEDS}

The simulated Current Acid Waste (CAW) composition is given in Table A.1. The composition of the CAW Frit 82-10 is presented in Table A.2 while Table A.3 shows the composition of the CAW raw-chemical glass formers. As discussed in Section 4, the raw-chemical glass formers are preferred over frits. The reference CAW slurry is made by adding raw-chemical glass formers to the CAW in $300 \mathrm{~g} / \mathrm{L}$ total oxides loading.

The simulated West Valley acid waste (WVAW) composition is given in Table A.4. The composition of the WVAW raw-chenical glass formers is given in Table A.5. The West Valley acid waste slurry is made by adding raw-chemical glass formers to the waste in a $330 \mathrm{~g} / \mathrm{h}$ total oxides loading.

Early in the rheology research, it was found that the order in which chemicals were combined affected the rheology of the simulated waste. This was due to the reduction in solubility of certain species caused by the presence of other species. By identifying the least soluble species and adding them first, all species in the simulated waste are dissolved. In preparing WVAW this meant that $\mathrm{NaNO}_{3}, \mathrm{NaSO}_{4}$ and $2 \mathrm{rO}\left(\mathrm{NO}_{3}\right)_{2} \cdot 2 \mathrm{H}_{2} \mathrm{O}$ were added first to an agitated feed make-up vessel (initially charged with warm water).

If frits are used, they are added last to the make-up vessel, completing the preparation of the melter feed. If raw chemicals rather than frits are used, then each raw chemical component is added separately to the simulated waste-containing make-up vessel. To determine an order of addition of the glass-former chemicals, it is beneficial to perform beaker studies in which each glass former is added and relevant observations are made. Based on the observations, an order of addition is established. An an example, Table A.6 lists the beaker-scale observations associated with each glass-former component mixed with WVAW. Table A.7 lists the best order of addition as suggested by the beaker-scale observations. 
TABLE A.1. Composition of Simulated Current Acid Waste (CAW)

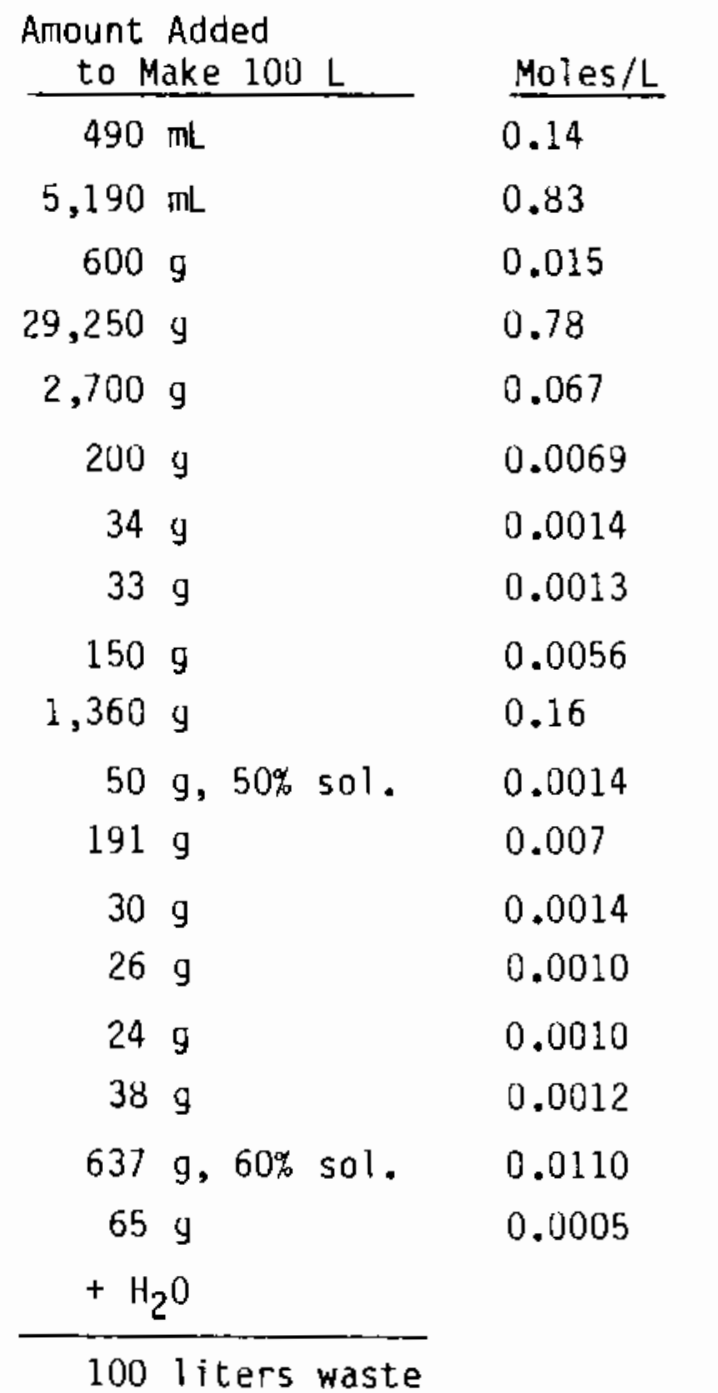

TABLE A.2. Composition of Frit 82-10

\begin{tabular}{ccc} 
Compound & & wt\% \\
\cline { 1 - 1 } $\mathrm{SiO}_{2}$ & & 61.7 \\
$\mathrm{~B}_{2} \mathrm{O}_{3}$ & & 15.1 \\
$\mathrm{Na}_{2} \mathrm{O}$ & 14.7 \\
$\mathrm{Li}_{2} \mathrm{O}$ & 7.4 \\
$\mathrm{MgO}$ & & 1.1
\end{tabular}


TABLE A.3. Composition of CAW Raw-Chemical Glass Former

\begin{tabular}{lr}
\multicolumn{1}{c}{ Compound } & $\frac{w t \%}{37.2}$ \\
$\mathrm{SiO}_{2}$ & 15.2 \\
$\mathrm{Na}_{2} \mathrm{~B}_{4} \mathrm{O}_{7}$ & \\
$\mathrm{Na}_{2} \mathrm{SiO}_{3} \cdot 5 \mathrm{H}_{2} \mathrm{O}$ & 19.1 \\
$\mathrm{LiNO}$ & 23.7 \\
$\mathrm{Mg}\left(\mathrm{NO}_{3}\right)_{2} \cdot 6 \mathrm{H}_{2} \mathrm{O}$ & 4.8
\end{tabular}

IABLE A.4. Composition of West Valley Acidic Waste

\begin{tabular}{lr}
\multicolumn{1}{c}{ Compound } & \multicolumn{1}{c}{$g / \mathrm{L}$} \\
$\mathrm{NaNO}_{3}$ & 89.95 \\
$\mathrm{Na}_{2} \mathrm{SO}_{4}$ & 6.20 \\
$\mathrm{ZrO}\left(\mathrm{NO}_{3}\right)_{2} \cdot 2 \mathrm{H}_{2} \mathrm{O}$ & 16.26 \\
$\mathrm{Fe}\left(\mathrm{NO}_{3}\right)_{3} \cdot 9 \mathrm{H}_{2} \mathrm{O}$ & 235.19 \\
$\mathrm{Cr}\left(\mathrm{NO}_{3}\right)_{3} \cdot 9 \mathrm{H}_{2} \mathrm{O}$ & 14.94 \\
$\mathrm{Na}_{3} \mathrm{PO}_{4} \cdot 12 \mathrm{H}_{2} \mathrm{O}$ & 0.70 \\
$\mathrm{Nd}\left(\mathrm{NO}_{3}\right)_{3} \cdot 6 \mathrm{H}_{2} \mathrm{O}$ & 3.65 \\
$\mathrm{Al}\left(\mathrm{NO}_{3}\right)_{3} \cdot 9 \mathrm{H}_{2} \mathrm{O}$ & 16.18 \\
$\mathrm{Mr}\left(\mathrm{NO}_{3}\right)_{2} \cdot 4 \mathrm{H}_{2} \mathrm{O}$ & 6.35 \\
$\mathrm{Ni}\left(\mathrm{NO}_{3}\right)_{2} \cdot 6 \mathrm{H}_{2} \mathrm{O}$ & 7.01 \\
$\mathrm{KNO}$ & 3.65 \\
$\mathrm{CSNO}$ & 0.55 \\
$\mathrm{RuO}$ & 0.08 \\
$\mathrm{Sr}_{2}\left(\mathrm{NO}_{3}\right)_{2}$ & 0.27 \\
$\mathrm{RE}\left(\mathrm{NO}_{3}\right)_{3}$ & 2.36 \\
$\mathrm{Na}_{2} \mathrm{MOO}_{4} \cdot 2 \mathrm{H}_{2} \mathrm{O}$ & 0.12 \\
$\mathrm{H}_{3} \mathrm{PO}_{4}$ & 14.17 \\
$\mathrm{HNO}_{3}$ & 126.0
\end{tabular}


TABLE A.5. Raw-Chemical Glass-Former Concentrations in west Valley Feed

\begin{tabular}{|c|c|}
\hline Compound & $g / L$ \\
\hline $\mathrm{SiO}_{2}$ & 147.65 \\
\hline $\mathrm{Na}_{2} \mathrm{SiO}_{3} \cdot 5 \mathrm{H}_{2} \mathrm{O}$ & 2.29 \\
\hline $\mathrm{Na}_{2} \mathrm{~B}_{4} \mathrm{O}_{7}$ & 43.93 \\
\hline $\mathrm{LiNO}_{3}$ & 54.91 \\
\hline $\mathrm{Mg}\left(\mathrm{NO}_{3}\right)_{2} \cdot 6 \mathrm{H}_{2} \mathrm{O}$ & 27.35 \\
\hline $\mathrm{ZrO}\left(\mathrm{NO}_{3}\right)_{2} \cdot 2 \mathrm{H}_{2} \mathrm{O}$ & 2.17 \\
\hline $\mathrm{La}\left(\mathrm{NO}_{3}\right)_{3} \cdot 6 \mathrm{H}_{2} \mathrm{O}$ & 2.66 \\
\hline $\mathrm{TiO}_{2}$ & 2.00 \\
\hline
\end{tabular}

TABLE A.6. Proposed Order for Adding Raw-Chemical Glass Formers

$\begin{array}{ll}1 & \mathrm{ZrO}\left(\mathrm{NO}_{3}\right)_{2} \cdot 6 \mathrm{H}_{2} \\ 2 & \mathrm{Na}_{2} \mathrm{SiO}_{3} \cdot 5 \mathrm{H}_{2} \mathrm{O} \\ 3 & \mathrm{LiNO}_{3} \\ 4 & \mathrm{Na}_{2} \mathrm{~B}_{4} \mathrm{O}_{7} \\ 5 & \mathrm{La}\left(\mathrm{NO}_{3}\right)_{3} \cdot 6 \mathrm{H}_{2} \mathrm{O} \\ 6 & \mathrm{TiO}_{2} \\ 7 & \mathrm{Mg}\left(\mathrm{NO}_{3}\right)_{2} \\ 8 & \mathrm{SiO}_{2}\end{array}$

TABLE A.7. Behavior of Raw-Chemical Glass Formers when Mixed with Simulated West Valley Acid Waste

$\begin{array}{ll}2 \mathrm{rO}\left(\mathrm{NO}_{3}\right)_{2} & \text { Dissolves quickly: Exothermic } \\ \mathrm{Mg}\left(\mathrm{NO}_{3}\right)_{2} & \text { Dissolves easily: Endothermic } \\ \mathrm{TiO}_{2} & \text { Forms a paste fairly quickly } \\ \mathrm{LiNO}_{3} & \text { Dissolves slowly: Endothermic } \\ \mathrm{Na}_{2} \mathrm{SiO}_{3} \cdot 5 \mathrm{H}_{2} \mathrm{O} & \begin{array}{l}\text { Forms a paste, liberates gas, } \\ \text { turns reddish brown: Exothermic }\end{array} \\ \mathrm{Na}_{2} \mathrm{~B}_{4} \mathrm{O}_{7} & \text { Dissolves siowly } \\ \mathrm{SiO}_{2} & \text { Insoluble, forms an opaque, grey suspension } \\ \mathrm{La}\left(\mathrm{NO}_{3}\right)_{3} \cdot 6 \mathrm{H}_{2} \mathrm{O} & \text { Dissolves easily }\end{array}$


APPENDIX B

SIMULATED FEED PHYSICAL PROPERTY DATA 


\section{APPENDIX B \\ SIMULATED FEED PHYSICAL PROPERTY DATA}

\section{B.1 PHYSICAL PROPERTIES}

Effective viscosity, percent volume expansion and specific gravity measurements were performed on both Hanford current acid waste (CAW) simulated melter feed and West Valley acid waste (WVAW) simulated melter feed. These properties are discussed below alony with the methods used to measure them.

\section{B.1.1 Viscosity}

Viscosity is defined as the ratio of shear stress to shear rate. For Newtonian fluids, this ratio is constant over all shear stresses and shear rates at a given fluid temperature. (In general, viscosity decreases with increasing fluid temperature.) In many fluids, the ratio of shear stress to shear rate is not constant over a range of shear stresses and the fluid is said to be non-Newtonian. Four types of non-Newtonian behavior are present in the two melter feeds studied, causing a complex viscosity behavior that is not describable as a single, Newtonian parameter. The four deviations from Newtonian behavior are discussed next.

\section{B.1.1.1 Thixotropy}

An excellent definition of thixotropy as provided by Shaw (1980), is reprinted:

\footnotetext{
"Thixotropy is the time-dependent analogue of shear-thinning and plastic behaviour, and arises from somewhat similar causes. If a thixotropic system is allowed to stand and is then sheared at a constant rate, the apparent viscosity decreases with time until a balance between structural breakdown and structure re-formation is reached. If the sheared system is then allowed to stand, it eventually regains its original structure. A thixotropic hysteresis loop (Figure 9.6) [figure not included here] can be obtained by measuring the non-equilibrium shear stress as the shear rate is first increased and then decreased in a standard way.

Solutions of high polymers are, in general, thixotropic to a certain extent; intermolecular attractions and entanglements are overome and the extent of solvent immobilisation is reduced on shearing, while Brownian motion restores the system to its original condition when left to stand. The classical examples of thixotropic behaviour are given by the weak gel
} 
systems, such as flocculated sols of iron(III) oxide, alumina and many clays (particularly bentonite clays), which can be 'iiquefied' on shaking and 'solidify' on standing. Thixotropy is particularly important in the paint industry, as it is desirable that the paint should flow only when being brushed on to the appropriate surface (high rate of shear) and immediately after brushing."

Both WVAW (waste) and CAW/Colloidal silica (feed) were found to be thixotropic.

\section{B.1.1.2 Pseudoplasticity}

A fluid having a viscosity that decreases with increasing shear stress is called a pseudoplastic. The phrase "shear thinning" is synonymous with "pseudoplastic" and is preferred in this report as the more descriptive term. The behavior of both the CAW and WVAW melter feed slurries was found to be shear-thinning. It is important to note that the shear-thinning behavior is exhibited when the glass-former particles are in suspension during the viscosity measurement. The behavior of the supernatant is predicted as being Newtonian after complete sedimentation occurs.

\section{B.1.1.3 Bingham Plasticity}

A fluid that exhibits a minimur shear stress above which it behaves as a free-flowing fluid, and below which it behaves as a nonflowing solid is called a Bingham plastic. CAW feed prepared with colloidal silica exhibits Bingham plastic behaviors. Until stirred, this feed behaves as a stiff gel having a consistency similar to that of cold cream. When stirred, or stressed beyond the so-called yield stress, the feed is transformed into a free-flowing fluid with a consistency similar to that of milk. Flocculated sediments also typically exhibit Bingham plasticity. The measurement of characteristic yield stress was not performed since the required equipment was not available.

\section{B.1.1.4 Dilatancy}

A fluid having a viscosity that increases with increasing shear stress is dilatancy. Dilatancy is exhibited by most nonflocculated feed-slurry sediments and is due mainly to the resistance to capillary flow, as discussed in Section 3.1.1. Thixotropy was observed in CAW/frit sediments and is a major 
contributor to the formation of clogs. Measurement of sediment dilatancy was not performed since a method to do so does not currently exist.

\section{B.1.1.5 Brookefield Viscometry}

All viscosity measurements were performed using a Brookefield viscometer. A spindle is rotated at a known rate through the fluid, and the torque required to maintain rotation is measured. The torque reading is divided by the spindle rotation rate ( $r p m$ ) and multiplied by a constant (spindle factor) to obtain a viscosity value. The spindle number and rpm are reported with the viscosity data presented in Sections B.2 and B.3. Since viscosity is dependent on temperature, all measurements were performed with the sample containers immersed in a $22^{\circ} \mathrm{C} \pm 1{ }^{\circ} \mathrm{C}$ constant temperature bath. A modification to the Brookefield viscometer was developed at PNL for the measurement of fluids containing settling solids. Unlike the standard Brookefield method, the PNL modification provides sufficient agitation to maintain the particles in suspension during the measurement.

\section{B.1.2 Percent Volume Expansion}

The percent volume expansion refers to the increase in volume of a melter. feed as glass-former solids are added. The resultant increase in volume, expressed as the percent increase in volume relative to the initial volume containing the waste solution only, is required to predict the final volume of feed corresponding to the combined mass of the waste and glass-former components. The final volume and corresponding mass must be known to calculate the feed density. In addition, the final volume must be known to calculate concentrations of the chemical constituents in the feed. Thus a correct feed recipe requires volume expansion data.

Since the actual volume expansion of the simulated acid waste stream was not known prior to the rheological work, and since this value must be known accurately to "back out" a representative acid waste stream composition from the reference Hest Valley melter feed slurry recipe, a series of experiments was performed to ascertain volume expansion. In these experiments, the volume increase of a sample of simulated acid waste as a function of raw-chemical glass-former loading was noted. The volume expansion data are presented in Sections B.2 and B.3. For clarity, an example (sample calculation) is provided below. 
Derivation of a Representative Waste Stream Composition from a Proposed

Melter Feed Slurry Recipe

Starting with the recipe given in Table A.1, to calculate the simulated waste stream concentrations we must first delete the glass former and then correct the remaining simulated waste concentrations for the volume change that would result from the deletion of the glass formers. From Table A.1, the expected total oxide loading is $330 \mathrm{~g} / \mathrm{L}$. Osing simple stoichiometry, this is then converted to a glass-former oxide loading of $213 \mathrm{~g} / \mathrm{L}$. From the data plotted in Figure B.1, a volume expansion of $\sim 16 \%$ corresponds to a $213-\mathrm{g} / \mathrm{L}$ glass-former oxide loading. (The total volume of the waste stream increases $\sim 16 \%$ when glass formers are added to make a $330-\mathrm{g} / \mathrm{L}$ total oxide loading.)

To "back out" the concentration of each constituent in the simulated waste stream from the simulated slurry recipe, the concentration given in the slurry recipe is increased in percentage by the volume expansion percentage associated with the glass-former oxide loading. As previously mentioned, for the case of a $213 \mathrm{~g} / \mathrm{L}$ glass-former oxide loading (reference case), the associated percent volume expansion (Figure B.1) is $16 \%$. Thus the concentration of each simulated waste constituent is multiplied, for this reference case, by 1.16 .

Example

The concentration of $\mathrm{HNO}_{3}$ in Table $\mathrm{A.l}$ is $126 \mathrm{~g} / \mathrm{L}$, so its corresponding concentration in the simulated waste stream is $1.16 \times 126 \mathrm{~g} / \mathrm{L}=146.2 \mathrm{~g} / \mathrm{L}$.

To determine the initial volume of waste before the addition of glass former (on a per liter of slurry basis):

$$
\frac{1}{1.16}=0.862 \mathrm{~L}
$$

meaning that 1 liter of the proposed melter feed slurry contains $862 \mathrm{~mL}$ simulated waste and $(1000-862=138 \mathrm{~mL}$ glass formers $)$.

It should be noted that since some of the glass formers dissolve, the volume percent of glass formers will always be greater than the actual volume percent solids. (This assumes no solids in the waste stream.) The volume percent solids is not currently known, but may be sought in further studies. 


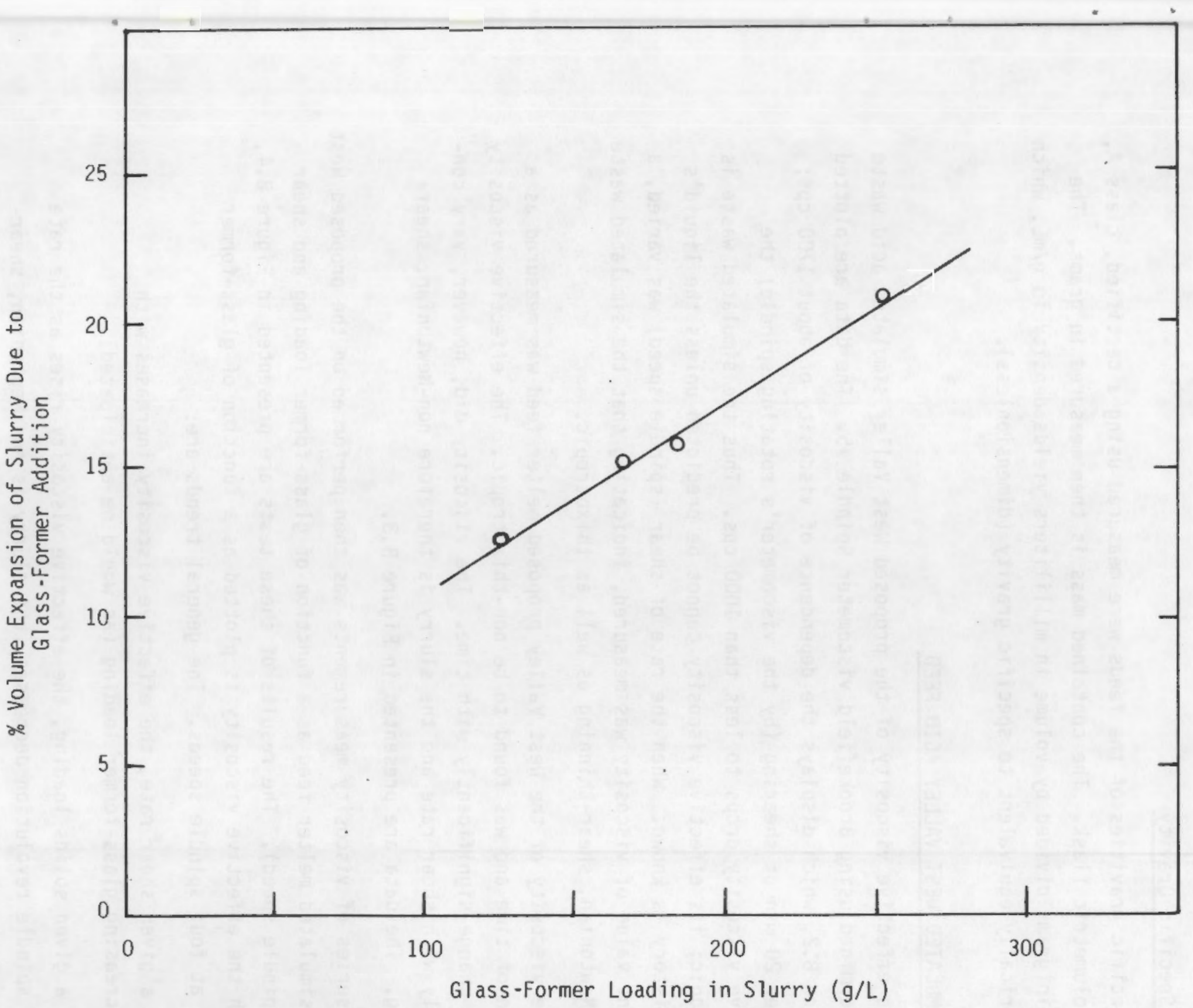

FIGURE B.1. Volume Expansion of Simulated West Valley Waste Versus Glass Former Loading, Near Reference Loading 


\section{B.1.3 Specific Gravity}

Specific gravities of the feeds were measured using a certified, class A, $25-\mathrm{mL}$ volumetric flask. The contained mass is then measured in grams. The weight in grams divided by volume in milliliters yields density in $\mathrm{g} / \mathrm{mL}$, which is numerically equivalent to specific gravity (dimensionless).

\section{B.2 SIMULATED WEST VALLEY ACID FEED}

The effective viscosity of the proposed West Valley simulated acid waste was determined using Brookefield viscometer Spindle \#5. The data are plotted in Figure B.2, which displays the dependence of viscosity of about $1700 \mathrm{cps}$; but after 20 min of shearing (by the viscometer's rotating spindle) the effective viscosity drops to less than $1000 \mathrm{cps}$. Thus the simulated waste is thixotropic; its effective viscosity cannot be predicted unless the liquid's shear history is known. When the rate of shear (spindle speed) was varied, a different value of viscosity was measured, indicating that the simulated waste is non-Newtonian, shear-thinning as well as thixotropic.

The viscosity of the West Valley proposed melter feed was measured as a function of time and was found to be non-thixotropic. The effective viscosity did not change significantly with time. The viscosity did, however, vary considerably with shear rate and the slurry is therefore non-Newtonian, shearthinning. The data are presented in Figure B.3.

A series of viscosity measurements was then performed on the proposed West Valley simulated melter feed as a function of glass-former loading and shear rate (spindle speed). The results of these tests are presented in Figure $\mathrm{B.4}$, in which the effective viscosity is plotted as a function of glass-former loading at four spindle speeds. The general trends are:

- At a given shear rate, the effective viscosity increases with increasing glass-former loading (as would be anticipated).

- At a given solids loading, the effective viscosity rises as the rate of spindle revolution decreases (the slurry is non-Newtonian, shearthinning). 


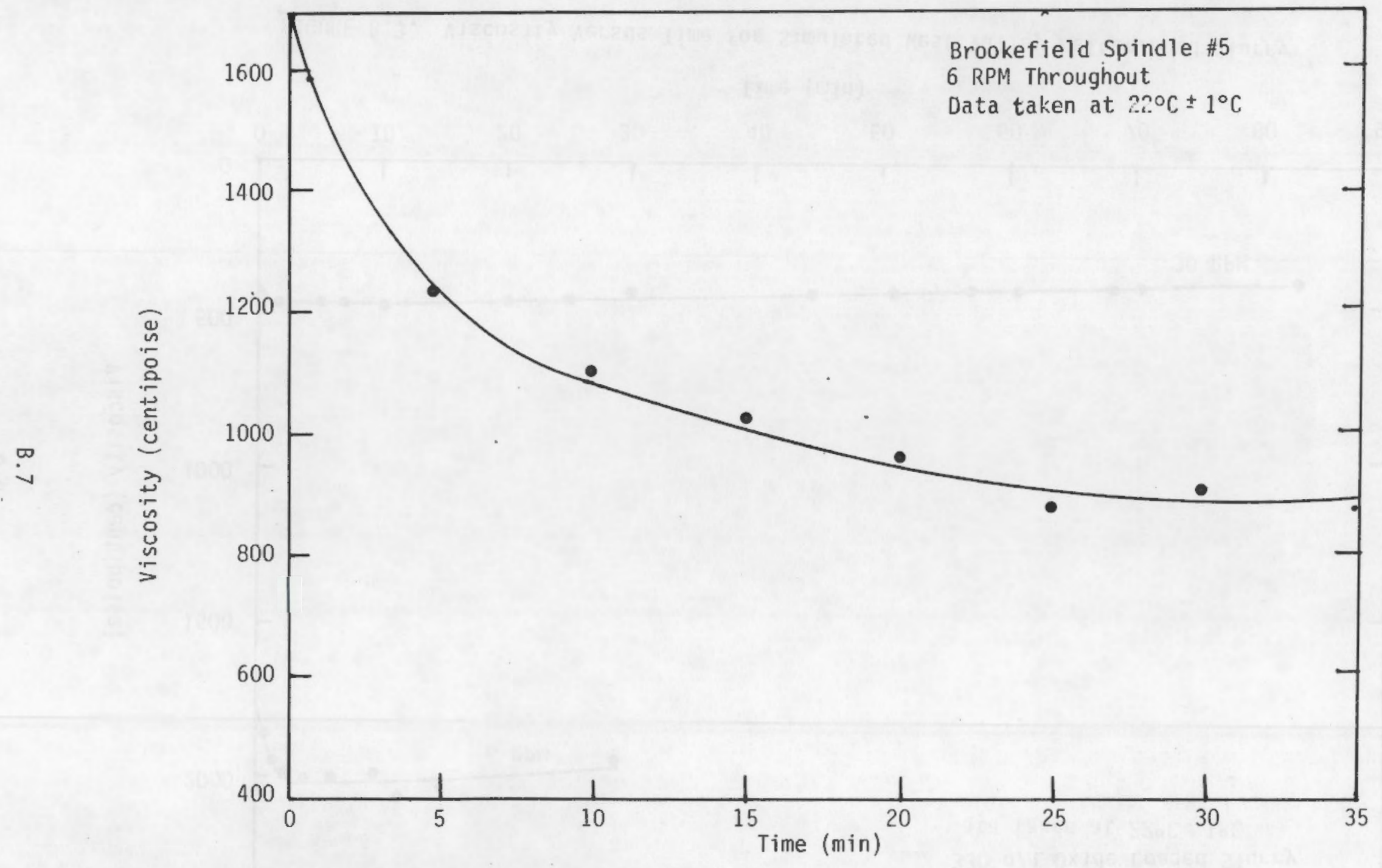

FIGURE B.2. Viscosity Versus Time for Simulated West Valley Acid Waste 


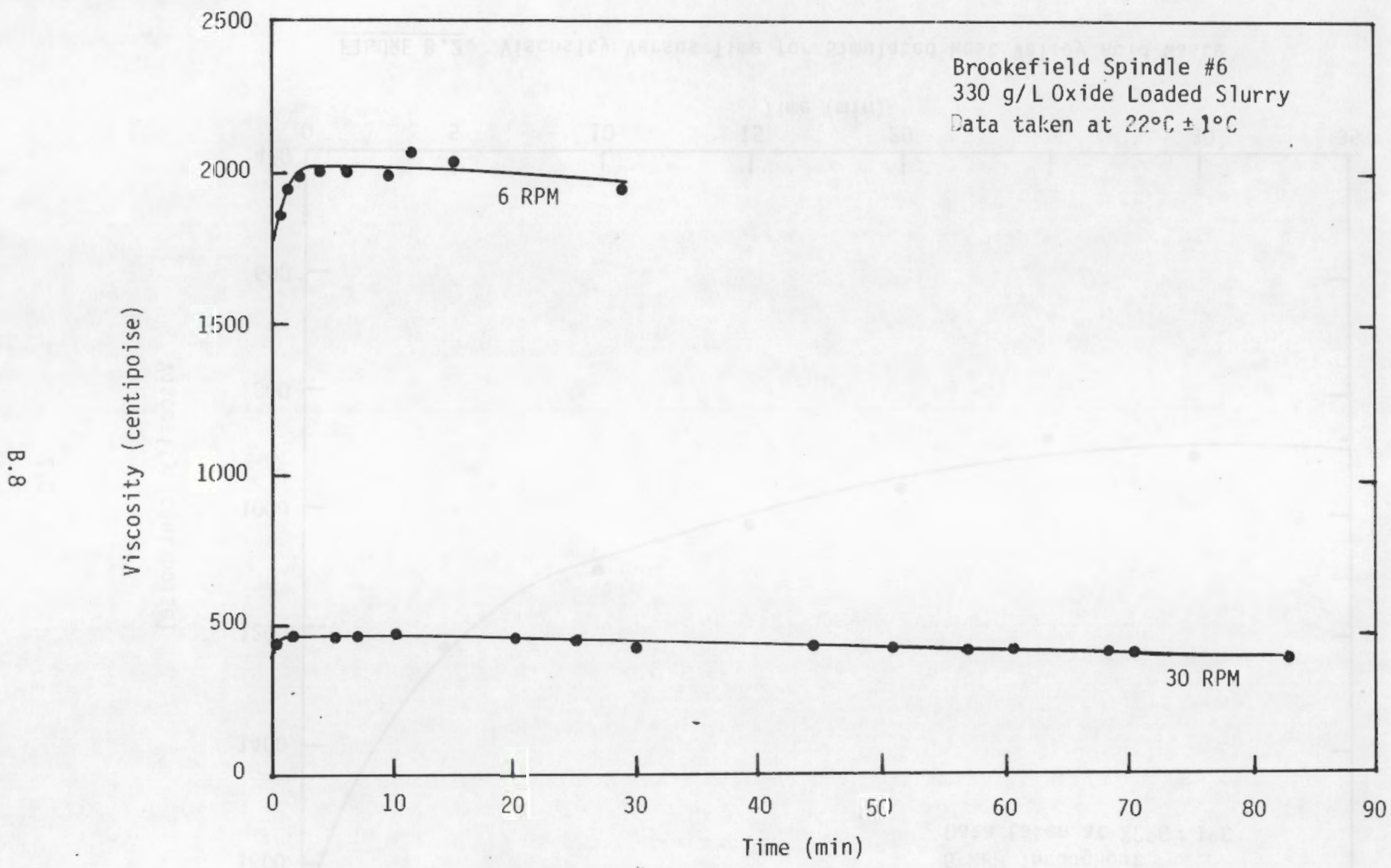

FIGURE B.3. Viscosity Versus Time for Simulated West Valley Melter Feed Slurry 


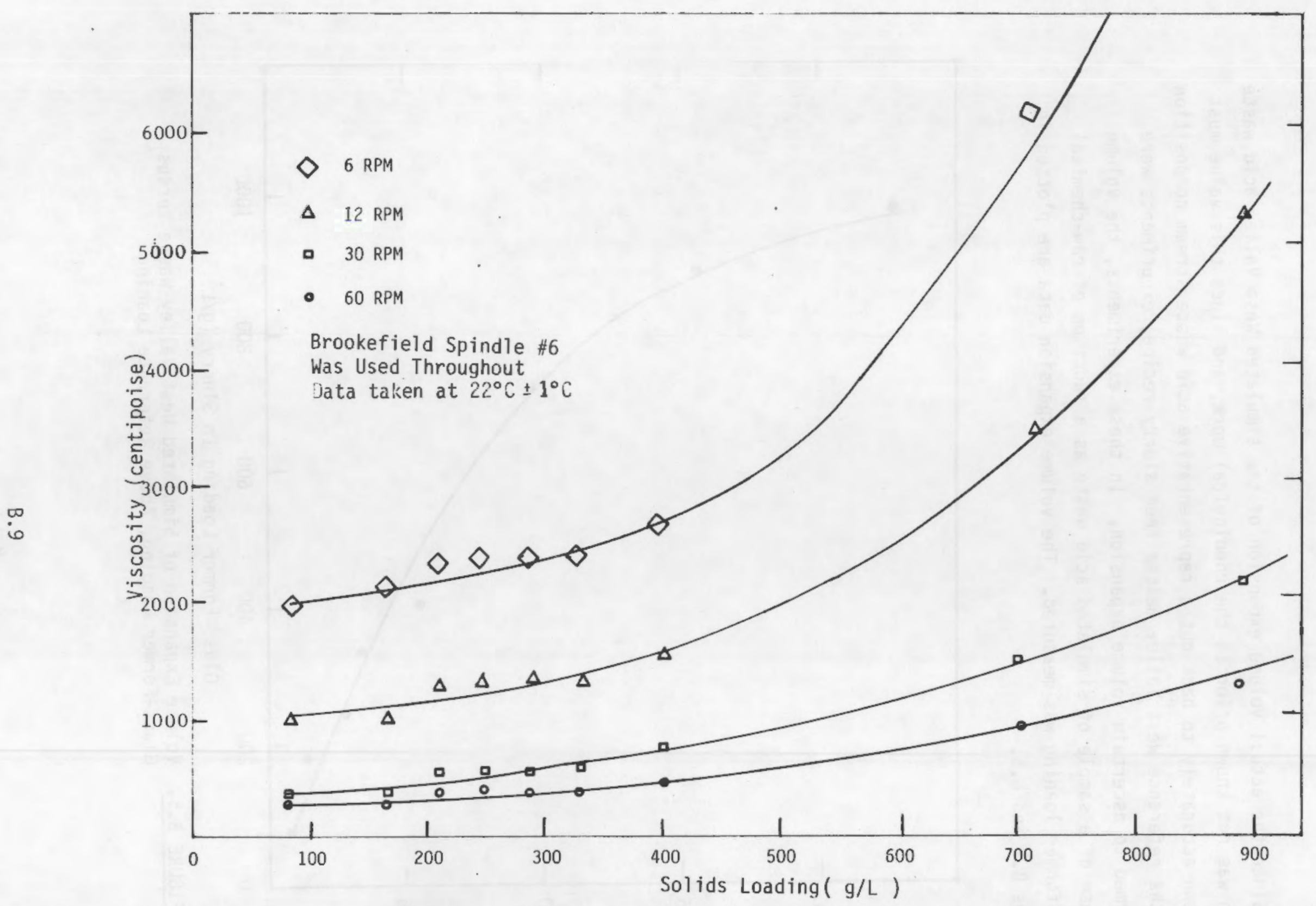

FIGURE B.4. Viscosity Versus Solids Loading and Shear Rate for Simulated West Valley Melter Feed Slurry 
Since the actual volume expansion of the simulated West Vailey acid waste stream was not known prior to the rheological work, and since this value must be known accurately to back out a representative acid waste stream composition from the reference West Valley melter feed slurry recipe, experiments were performed to ascertain volume expansion. In these experiments, the volume increase of a sample of simulated acid waste as a function of raw-chemical glass-former loading was measured. The volume expansion data are plotted in Figures $B .1$ and $B .5$.

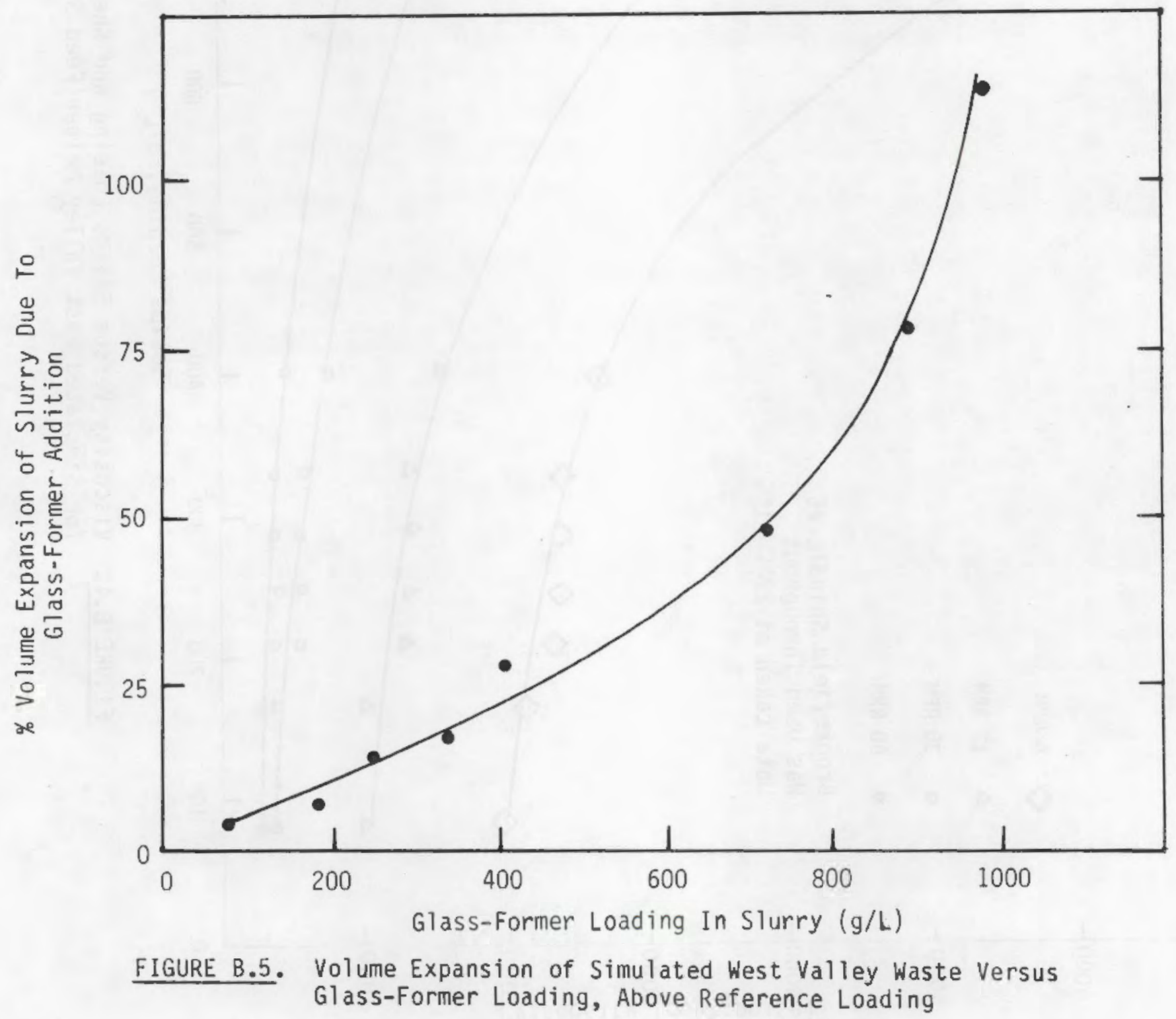




\section{B.3 HANFORD CURRENT ACID WASTE (CAW) SIMULATED FEED}

The specific gravity of CAW slurry was measured as $1.35 \pm 0.01$. Figure B.6 shows the effective viscosity of CAW slurry as a function of Frit 82-10 loading.

The viscosities plotted in Figure B. 6 were measured at a single shear rate (30 rpm, Brookefield Spindle $\# 3$ ) and at one temperature $\left(22^{\circ} \mathrm{C} \pm 1^{\circ} \mathrm{C}\right.$ ), but are, in general, dependent upon both shear rate and temperature. Changes in solids loading $\pm 100 \%$ from reference can be seen to have little effect on CAW slurry viscosities.

Volume percent expansion due to the addition of Frit $82-10$ is plotted in Figure B.7.

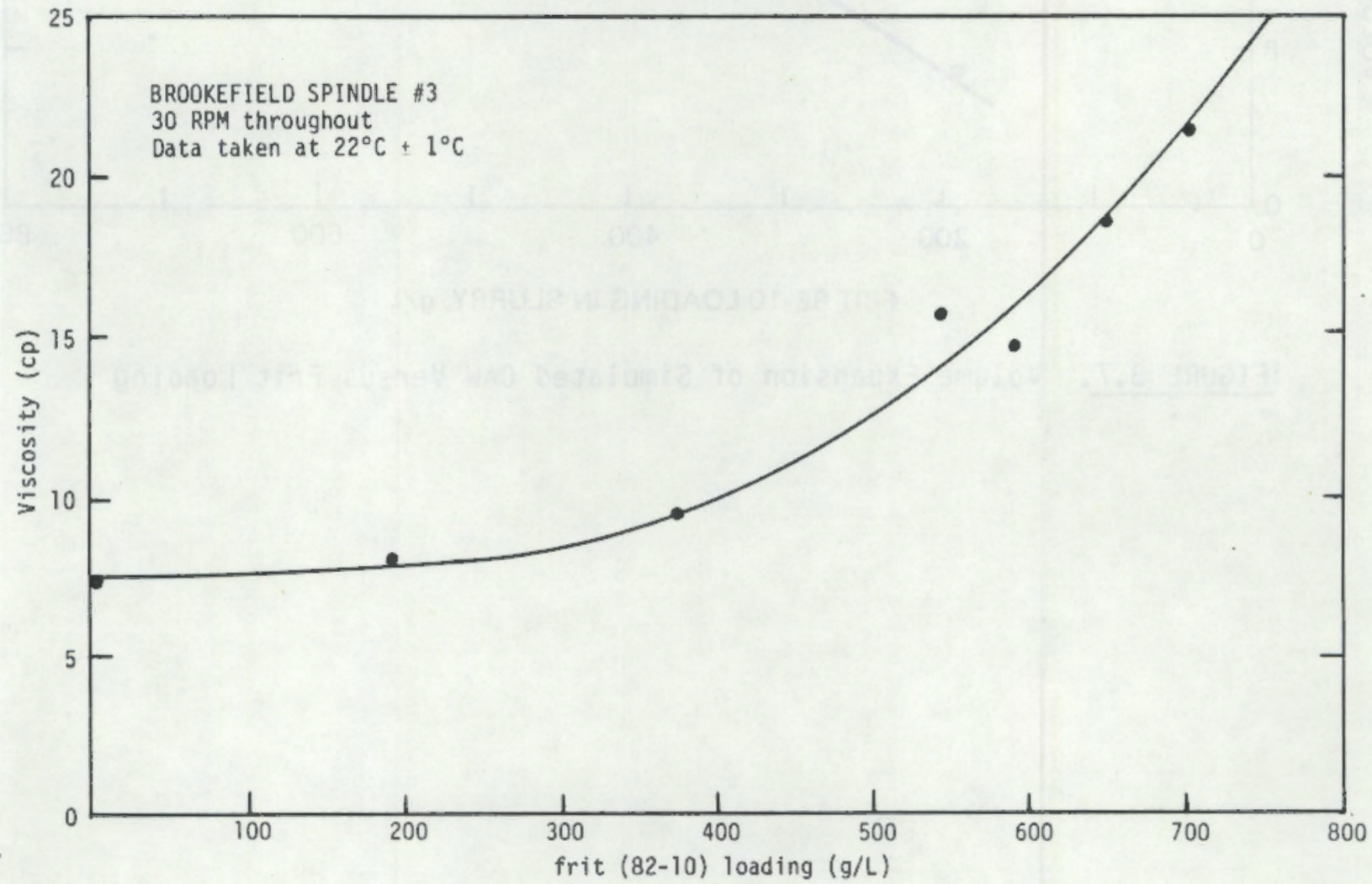

FIGURE B.6. Viscosity Versus Solids Loading for CAW Simulated Melted Slurry 


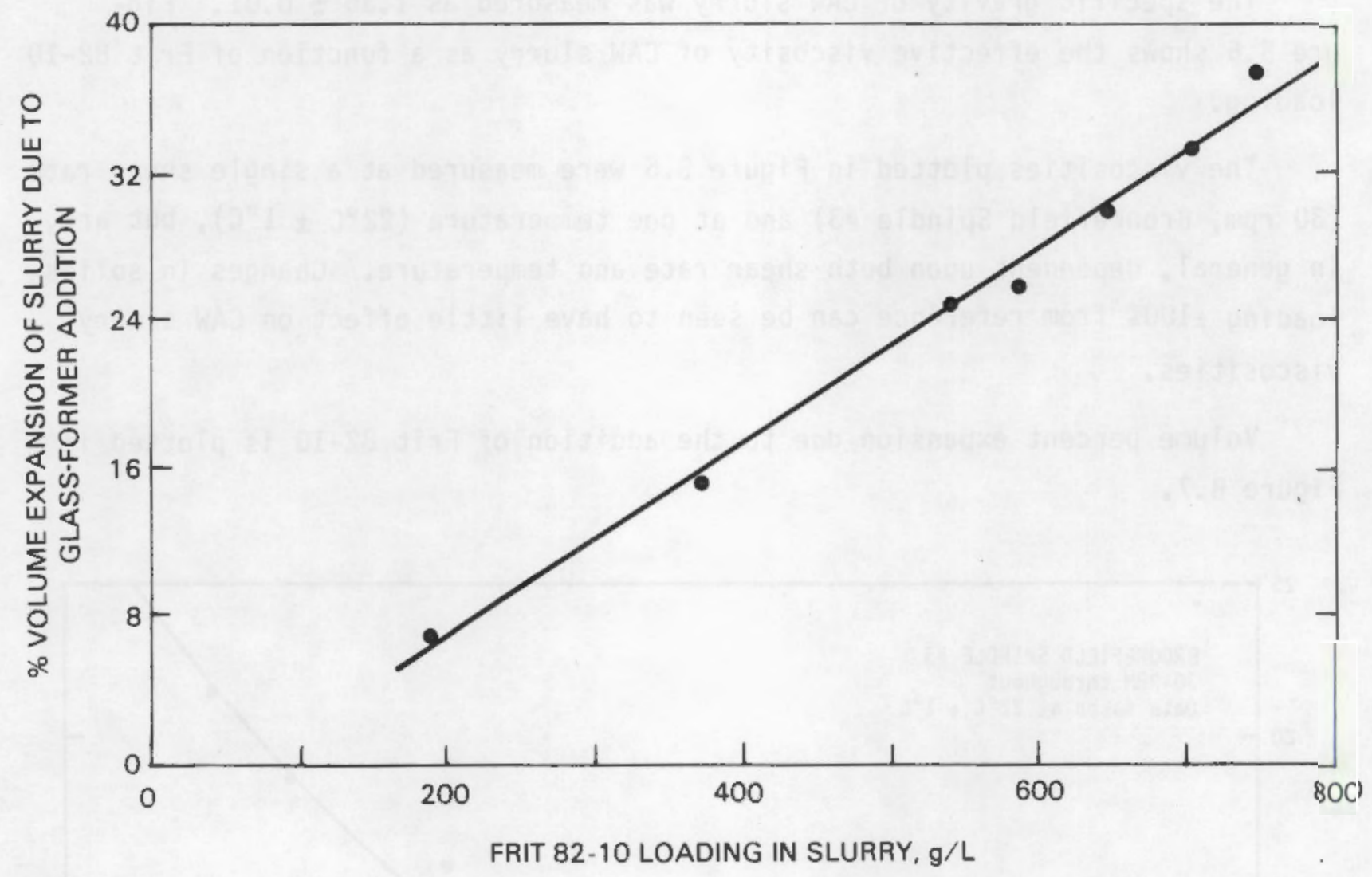

FIGURE B.7. Volume Expansion of Simulated CAW Versus Frit Loading 


\section{DISTRIBUTION}

No. of

Copies

OFFSITE

27 DOE Technical Information Center

W. W. Ballard, Jr.

DOE Office of Spent Fuel

Management \& Reprocessing

Systems

NE-40, GTN

Washington, DC 20545

4 Geologic Repository Division

DOE Nuclear Waste Policy Act

Project office

GTN

Washington, DC 20545

ATTN: J. W. Bennett, RW-20

C. R. Cooley

R. Stein

M. H. Frei

M. J. Lawrence

DOE Nuclear Waste Policy Act Project office

S-10, Forrestal

Washington, DC 20585

D. B. LeClaire

DOE Office of Defense Waste \& Byproducts Management

DP-12, GTN

Washington DC 20545

5 DOE Terminat Waste Disposal \& Remedial Action

GTN

Washington, DC 20545

ATTN: J. E. Baublitz, NE-24

F. E. Coffman, NE-20

J. A. Coleman, NE-25

J. A. Turi, NE-25

D. E. Shelor, $N E-25$
No. of

Copies

2 DOE Albuquerque Operations Office

P.0. Box 5400

Albuquerque, NM 87185

ATTN: R. Y. Lowrey

J. MCGough

W. H. Hannum

DOE West Valley Operations

Office

P.0. Box 191

West Valley, NY 14171

2 DOE Idaho Operations Office

550 Second Street

Idaho Falls, ID 83401

ATTN: J. D. Hamric

J. B. Whitsett

L. Lanni

DOE San Francisco Operations

1333 Broddway

San Fransico, CA 94612

D. E. Large

DOE Oak Ridge Operations Office

P.0. Box E

Dak Ridge, TN 37830

S. A. Mann

DOE Chicago Operations Office

9800 South Cass Avenue

Aryonne, IL 60439

J. 0. Neff

DOE National Waste Program Office

505 King Avenue

Columbus, $\mathrm{OH} 43201$ 
No. of

Copies

3 DOE Savannah River Operations Office

P.0. Box A

Aiken, SC 29801

ATTN: E. S. Golberg

T. B. Hindman

G. K. Oertel

D. L. Vieth

DOE Nevada Operations Office

P.0. Box 14100

Las Vegas, NV 89114

2 Argonne National Laboratory

9700 South Cass Avenue

Argonne, IL 60439

ATTN: C. S. Abrams/J. H. Kittel

M. J. Steindier/L. E. Trevorrow

5 Battelle Memorial Institute Project Management Division $505 \mathrm{King}$ Avenue

Columbus, $\mathrm{OH} 43201$

ATTN: W. A. Carbeiner/S. H. Basham

N. E. Carter

S. Goldsmith/J. F. Kircher

W. J. Madia

B. Rawles

F. Holzer

Lawrence Livermore National Laboratory

University of California

P.0. Box 808

Livermore, CA 94550

D. T. Oakley, MS 671

Los Alamos Scientific Laboratory

P.0. Box 1663

Los Alamos, NM 87544
No. of

Copies

T. H. Row

Oak Ridge National Laboratory

P.0. Box $X$

Oak Ridge, TN 37830

W. D. Burch

Oak Ridge National Laboratory

P.0. Box $Y$

Oak Ridge, TN 37830

5 Sandia Laboratories

P.0. Box 5800

Albuquerque, NM 87185

ATTN: $0 . R$. Anderson

R. M. Jefferson

R. W. Lynch

W. Weart

Technical Library

B. R. Wheeler

Westinghouse Idaho Nuclear

Co., Inc.

P.0. Box 4000

Idaho Falls, ID 83401

3 E. 1. du Pont de Nemours Company

Savannah River Laboratory

Aiken, SC 29801

ATTN: J. L. Crandall

E. J. Hennelly

S. Mirshak

E. A. Jennrich

EG\&G Idaho

P.0. Box 1625

Idaho Falls, I0 83415

K. V. Gilbert/P. G. Hagen

Rockwell International

Rocky Flats Plant

P.0. Box 464

Golden, C0 80401 
No. of

Copies

G. W. Meyers

Atomics International Division

Rockwell International

8900 DeSoto Avenue

Canogo Park, CA 91304

T. H. Pigford

Department of Nuclear

Engineering

University of California

Berkeley, CA 94720

M. E. Spaeth

Science Applications, Inc.

2769 South Highland

Las Vegas, NV 89109

J. F. Strahl

Weston

2301 Research Boulevard

Third Floor

Rockville, M 20850

R. L. Ternes

5916 8th NE

Seattle, WA 98105

R. Willians

Electric Power Research

Institute

3412 Hillview Avenue

P.0. Box 10412

Palo Alto, CA 94304

4 West Valley Nuclear Services

Company

P.0. Box 191

Albuquerque, NM 87185

ATTN: C. C. Chapman

J. L. Knabenschuh

J. E. Krauss

J. M. Pope

J. W. Bartlett

The Analytic Sciences

Corporation

6 Jacob Way

Reading, MA 01867
No. of

Copies

W. A. Freeby/J. L. Jardine

Bechtel National, Inc.

P.0. Box 3965

San Francisco, CA 94119

R. K. Brown

Westinghouse Electric

Corporation

Advanced Energy Systems

Division

WIPP Library

P.0. Box 40039

Albuquerque, NM 87196

L. L. Hench

Department of Materials Science

\& Engineering

University of Florida

Gainesville, FL 32611

J. L. Larocca, Chairman

Energy Research \& Development Authority

Empire State Plaza

Albany, NY 12223

R. G. Post

College of Engineering

Univerity of Arizona

Tucson, AZ 85721

\section{ONSITE}

6 DOE Richland 0perations office

J. H. Antonnen/P. A. Craig

0. J. Elgert

H. E. Ransom

M. W. Shupe

J. D. White/R. D. Izatt

J. J. Broderick 
No: of

Copies

7 Rockwe?1 Hanford Dperations

R. N. rurley

H. E. MCGuire

K. R. Shah

R. J. Thompson

D. D. Wodrich

B. A. Wolfe

File Copy

UNC United Nuclear Industries

T. E. Dabrowski/W. J. Kyriazis

2 Westinghouse Hanford Company

A. G. Blasewitz/J. D. Watrous

R. E. Lerch

67 Pacific Northwest Laboratory

R. P. Allen

W. J. Bjorklund

H. T. Blair

W. F. Bonner

R. A. Brouns

L. L. Burger/L. A. Bray/ R. D. Scheele

H. C. Burkholder

J. R. Carrell
No. of

Copies

Pacific Northwest Laboratory

L. A. Chick

T. D. Chikalia

M. S. Hanson

C. D. Harvey

W. D. Heath (25)

L. K. Holton

3. H. Jarrett/D. J. Bradley

D. E. Knowlton

W. L. Kuhn

L. T. Lakey/K. M. Harmon

D. E. Larson

J. M. Latkovich/C. A. Geffen

R. C. Lijkala/M. R. Kreiter

R. P. Marshall/W. R. Wiley/

D. B. Cearlock

J. L. MCE l roy

R. W. McKee

J. E. Mendel/M. D. Merz

J. E. Minor

J. M. Perez

A. M. Platt

J. A. Powell

J. V. Robinson

W. A. Ross

J. M. Rusin

N. M. Sherer

G. L. Tingey/G. A. Jensen

R. P. Turcotte/G. L. McVay

H. H. Van Tuyl

Technical Information (5)

Publishing Coordination (2) 